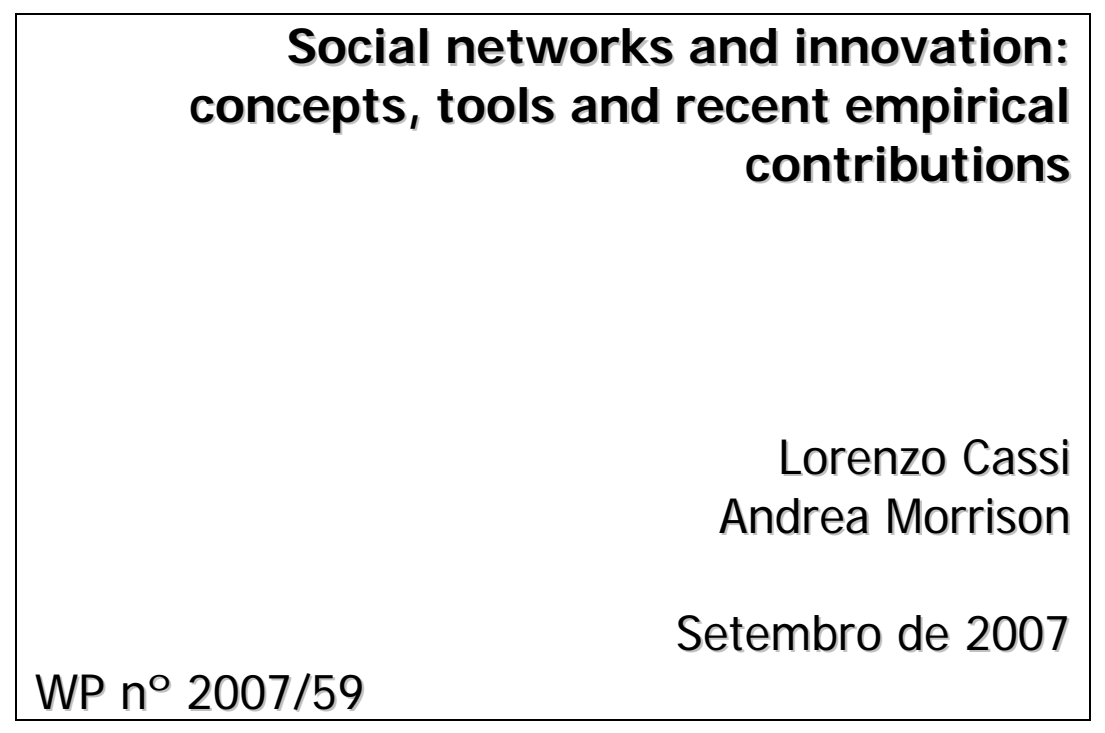

DOCUMENTO DE TRABALHO WORKI NG PAPER 
Social networks and innovation:

concepts, tools and recent empirical contributions

Lorenzo Cassi ${ }^{1}$

Andrea Morrison $^{2}$

WP n $2007 / 59$

Setembro de 2007

\author{
Abstract
}

1. INTRODUCTION

5. THE BOUNDARIES OF SOCIAL RELATIONS: DEFINITION AND MEASUREMENT ISSUES

6. CONCLUSIONS

REFERENCES

\footnotetext{
${ }^{1}$ CESPRI, BOCCONI University (Milano), ADIS, Université Paris Sud.

${ }^{2}$ CESPRI, BOCCONI University (Milano) and UNIVERSITA' PIEMONTE ORIENTALE (Novara).

* This research was carried out within the Project ENTSOCNET - Social networks, entrepreneurs and access to knowledge: the case of biotechnology and the IT industries, funded by FCT - Fundação para a Ciência e a Tecnologia (POCI/ESC/60500/2004).
} 


\section{Social networks and innovation: concepts, tools and recent empirical contributions*}

\section{Abstract}

This paper reviews the most recent empirical literature dealing on social networks, knowledge diffusion and the innovative performance of firms. It aims to understand the extent to which the empirical literature on network and innovation addresses the key question of how social relations affect inter-firm knowledge flows. Reviewing the most recent and most significant empirical contributions in the field, we examine how social relations have been measured and defined and whether they affect inter-firm knowledge flows.

Keywords: Innovation, Knowledge Flows, Social Network, Inter-organisational Network

JEL classification: A12, O31, Z13

\footnotetext{
* The authors acknowledge funding by FCT project, ENTSOCNET (2005-2008), ran by DINAMIA-ISCTE and INETI (Lisbon). The authors wish to thank participants in the ENTSOCNET internal seminar held in Lisbon, 20 April 2007. Thanks to Ricardo Mamede for his careful reading of a previous version of the paper. The paper presents the analysis and opinion of the authors who are exclusively responsible for any mistakes and misconceptions.
} 
"Society is more ingenious than the market.",

\section{INTRODUCTION}

This paper reviews the most recent empirical literature dealing on social networks, knowledge diffusion and the innovative performance of firms. Theoretical and empirical studies have shown that the specific structures or properties of networks can positively or negatively affect the degree to which knowledge diffuses which in turn affects the performance of organisations. According to this literature, the existence of inter-firm relations and their effectiveness depend crucially on the social context in which economic agents are embedded. Therefore, in analysing these complex systems it is necessary to take account of inter-firm networks (e.g. R\&D alliances between firms) and social networks (e.g. interaction among former colleagues) and the wider community of technologists or experts. This is the conceptual framework for our review.

The paper is structured as follows. The second section introduces this conceptual framework, interpreting the connections between inter-firm relations and social ties. A taxonomy is proposed for on inter-firm knowledge flows. The third section presents some technical tools and a glossary of network analysis and graph theory designed to guide the reader through the empirical literature discussed in subsequent sections and also offers some insights on network construction and data collection. The expert reader may want to skip this part. The next two sections (4 and 5) constitute the core of this review. Section 4 reviews the studies on how social networks affect networks of organisations, in terms of both the formation of new links, either formal or informal, and innovative performance, either at individual or aggregate level. Section 5 highlights some methodological issues. In particular it provides some insights on the criteria used in the empirical literature to identify social networks. Section 6 concludes by summarising the main findings and pointing to some key issues for future research.

\footnotetext{
${ }^{3}$ In this way, Arrow (1987; p. 687) comments the argument put forward by Dasgupta and David in their paper "Information Disclosure and the Economics of Science and Technology”, in G. Feiwel (ed.) Arrow and the Ascent of Modern Economic Theory, NY University Press, pp. 519-542.
} 


\section{A CONCEPTUAL FRAMEWORK}

Analysis of social networks has emerged as a central issue in industrial organisation and in other strands of economics. The metaphorical use of the term network is common in the economics literature; ${ }^{4}$ but there are several theoretical and empirical studies that explicitly analyse the role of social networks, and how they constrain/enhance the economic action of individuals and organisations. Thus, we can argue that social network analysis and its accompanying concepts, ideas and technical tools are recognised and widely applied by scholars in economics and related fields. An important strand of this work is in those branches of economics that deal with knowledge and innovation. ${ }^{5}$ This literature has converged towards a common (at least, in operative terms) view of what is meant by an inter-organisational network. According to transaction cost economics (TCE), an approach that has influenced (and perhaps dominates) the modern theory of firm, an inter-organisational network can be reduced to a hybrid form of organisation between markets and hierarchies. Networks as inter-firm governance structures lie somewhere on the continuum between the two extremes (i.e. market and hierarchy), but have no specific features (Powell, 1990). However, the TCE view has been criticised for its lack of social dimension and for inability to deal with social embeddedness, ${ }^{6}$ which strongly characterises inter-organisational networks (see Ozman, 2006, for a review of this issue). Interorganisational networks are increasingly seen as a specific form of governance in which a set of organisations is linked through some relations involving a certain degree of trust and reciprocity (Powell, 1990). There is a wide variety of networks, which can be differentiated on several dimensions, for instance in terms of their duration and stability (Powell and Grodal, 2005). However they are classified, networks of organisations are socially embedded and distinguishes them from hierarchical organisations and markets. This analytical shift is of great relevance for the literature on networks and innovation. As Powell and Grodal (2005: 61) argue "[t]he extent to which inter-organisational ties are contingent upon relations among individuals is a key question for scholarly research”. However, analyses incorporate this view, with the result that there are many ambiguities and inconsistencies in the empirical literature on networks.

This paper aims to understand the extent to which the empirical literature on network and innovation addresses the key question of how social relations affect inter-firm knowledge flows. We review the most recent and most significant empirical contributions in the field; in particular, we examine how social

\footnotetext{
4 "The network appears well on its own way to becoming the transcendent symbol and dominant metaphor of the coming information century. Nowadays it seems that wherever we look, networks can be seen. [...] When describing come intricate technological, economic, social, or political arrangement we are inclined in place of clockwork to say network, possibly with not much more self awareness and critical effort than was expended when employing the previous metaphor.” [David et al., 1999; p. 314-315]

${ }^{5}$ We refer to business studies (mainly organisational studies), economics of innovation and economic geography (i.e., studies analysing the innovative performance of regional clusters).

${ }^{6}$ The manifesto of the embeddedness approach, i.e. Granovetter's article of 1985, is a radical critique of the TCE approach. According to Granovetter, embeddedness affects any aspect of human activity and any institution: “A fruitful analysis of human action requires us to avoid the atomisation implicit in the theoretical extremes of under- and over-socialised conceptions. Actors do not behave or decide as atoms outside a social context, nor do they adhere slavishly to a script written for them by a particular intersection of social categories that they happen to occupy. Their attempts at purposive action are instead embedded in concrete, ongoing systems of social relations. [...Social relations] are the structure that fulfils the function of sustaining order.” [Granovetter, 1985; p.487-491; emphasis added].
} 
relations have been measured and defined and whether they affect inter-firm knowledge flows. In relation to Figure 1, which depicts an inter-organisational (or inter-firm) network and its social counterpart (i.e. embedded relations), this means examining to what extent the bottom part of the figure (social network) interacts with the top part (inter-firm relations). ${ }^{7}$

Figure 1. Inter-firm networks, social networks and knowledge exchange

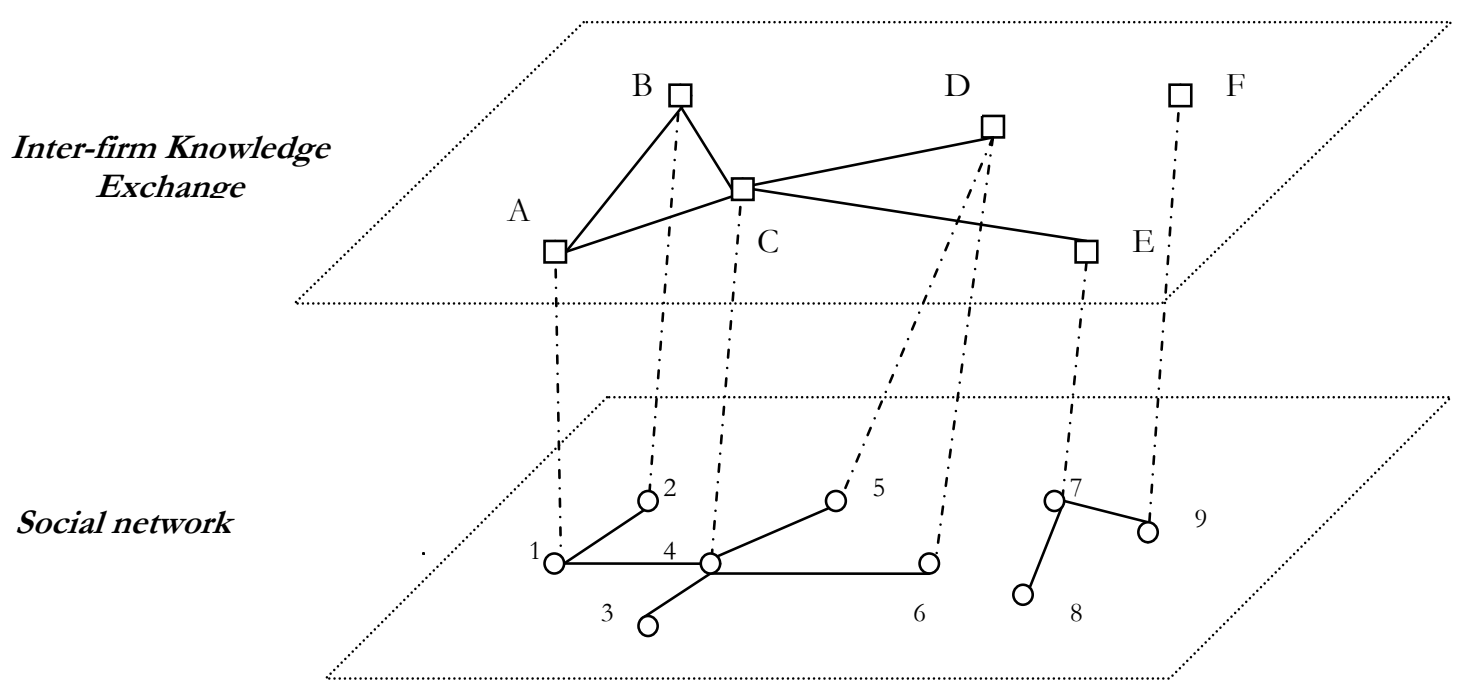

The top part of the figure depicts an inter-firm network comprised of six organisational actors, e.g. firms (squares: A-F), and their links (continuous line). Firms are assumed to belong to the same sector (or, in more general terms, to refer to the same potential knowledge base) and each link between two directly connected squares implies an exchange of knowledge. The bottom part of the figure describes the interindividual (or social) network, i.e. the set of social relations (the continuous line) existing among nine different individuals (i.e. the circles: 1-9). Individuals can be a population of experts whose know-how is relevant for the sector in which firms operate ${ }^{8}$ and which are socially linked (e.g. through friendship/social contact). Because some individuals work for firms in the inter-firm network (top part of the figure), the two levels are linked (dotted lines). ${ }^{9}$

Organisations exchange knowledge through many different channels and mechanisms; thus, social networks play different roles in determining or shaping these flows. It is worth distinguishing among the many different kinds of knowledge flows and mechanisms in use. Table 1 presents a simple taxonomy involving four different types of relations. They are not mutually exclusive, and may influence, overlap and

\footnotetext{
${ }^{7}$ We do not consider the reverse relation or their co-evolution.

${ }^{8}$ Defining the boundaries of the population of individuals is a tricky issue; a specific section of this study (Section 5) is dedicated to this issue.

${ }^{9}$ Please note that the some of individuals do not work for any of the firms in the top part in Figure 1. To show that, we illustrate them as disconnected from nodes in the top part, while connected with other nodes in the bottom part (see individuals 3 and 8).
} 
interweave with one another. The types of relations and transfer mechanisms linking organisations can be classified on two dimensions: formal vs. informal; unilateral vs. bilateral. The former depends on whether a formal agreement exists between two or more organisations; the latter indicates whether the exchange is mutual or not, i.e. whether knowledge flows in one or both directions. We briefly discuss each of these categories providing examples to illustrate how social networks affect knowledge exchanges among firms.

Table 1. Knowledge flows and channels of transmission

\begin{tabular}{|c|c|c|}
\hline & $\begin{array}{l}\text { Formal Agreement } \\
\text { Between Two Firms }\end{array}$ & $\begin{array}{c}\text { Informal or No Agreement } \\
\text { Between Two Firms }\end{array}$ \\
\hline $\begin{array}{c}\text { Unilateral } \\
\text { Knowledge Flow }\end{array}$ & $\begin{array}{c}(1) \\
\text { Licence/ } \\
\text { Equipment/Consultancy }\end{array}$ & $\begin{array}{c}(3) \\
\text { Job Mobility/ } \\
\text { Reverse Engineering }\end{array}$ \\
\hline $\begin{array}{c}\text { Bilateral } \\
\text { Knowledge Flow }\end{array}$ & $\begin{array}{c}(2) \\
\text { R\&D Alliance/ } \\
\text { Co-patenting activities }\end{array}$ & $\begin{array}{c}(4) \\
\text { Informal Know-How } \\
\text { Trading }\end{array}$ \\
\hline
\end{tabular}

In the top left (i.e. cell 1) of Table 1 we have exchanges of knowledge embodied in licences, consultancy and equipment. These interactions occur through market transactions and presumably do not entail the degree of personal contact implied by the other categories; they are often unilateral (i.e. from sellers to customers). Equipment, though, often includes some kind of technical assistance, which suggests an evolution towards more prolonged and informal interactions. The lower left cell (2) is characterised by formal technological agreements between firms, or co-patenting. As stated above these inter-firm networks rely on a number of more informal ties. Thus, formal agreements, although not explicitly aimed at enhancing information trading, may foster it. Job mobility (cell 3) is the most significant form of knowledge socialisation. Social networks foster job mobility by providing firms and workers with reliable information and by signalling opportunities. However, it is difficult to measure these flows, since the knowledge embodied in individuals (skills) is tacit. Labour mobility helps to forge new links among firms, since workers often maintain social contact with former colleagues, which increases the density of interorganisational networks. Former colleagues can been seen as potential sources of useful knowledge. Labour mobility therefore plays a central role as a channel for connecting previously unconnected firms and enhancing informal trading of know-how. The last channel of transmission (cell 4) describes these informal networks of individuals with a common understanding and code of communication. These groups include engineers and technicians employed by different firms, who interact intensively among themselves. In most cases these interactions are based on formal working agreements between their employer firms. 
In the two upper cells, the role of social networks consists mainly (but not exclusively) of providing intensive information (Rees, 1966) to individuals trading in well-defined markets (e.g. the labour or equipment market). As Granovetter (1974) shows in the context of job searching in labour markets, social networks provide individuals with better information than do other sources of information (e.g. job advertisement). The two cells in the bottom part of the table refer to the kind of knowledge, which rather than signalling opportunity, is personal, contextual and therefore difficult to transmit (i.e. know-how). Our review is concerned with the recent contributions on networks and innovation. Which generally focus on the mechanisms depicted in the bottom part of the taxonomy. We distinguish between the different mechanisms and types of knowledge transfer, particularly identifying knowledge flows that occur through formal ties and those that result from informal connections. Before discussing the main issues in the empirical literature we present some key concepts in social network analysis.

\section{SOCIAL NETWORK ANALYSIS: TOOLS AND DATA}

In examining the key concepts and tools of networks analysis we pay particular attention to the network measures widely used in the literature (e.g. degree centrality). Data collection methods are described in order to highlight differences in terms of conventional firm data. The three subsections in this part briefly describe the main concepts of network analysis, the network configuration widely used with patent data (i.e. two mode networks), and comment on the survey methodologies used for network data collection. It is important to stress that this section is not meant to be comprehensive. For an exhaustive and detailed analysis of methods and applications in network analysis see Wasserman and Faust (1994). ${ }^{10}$ For an updated work see Carrington et al. (2005), which report some of recent methodological topics debated in the literature.

\subsection{Social network concepts and tools}

The main analytical tool used in the studies reviewed here is graph theory and its applications, also known as social network analysis. This section discusses the key terminology and main concepts of social network analysis as used in the literature. Where appropriate, we refer explicitly to the type of data used.

A network can be defined as a set of actors (or nodes) linked by some kind of relational tie. A network thus defined can be visually depicted as a graph (socio-gram) in which the nodes are represented as points in a two-dimensional space and relationships among pairs of actors are represented by lines (edges or arcs) linking the corresponding points. The socio-gram in Fig. 2 illustrates a hypothetical network in which the nodes are the economic actors (e.g. organisations) and the lines represent knowledge transfers. The

\footnotetext{
${ }^{10}$ There are several books dealing with the methods and tools of social network analysis. Wasserman and Faust is probably the most popular and most cited, but Degenne and Forsè (1999), Scott (2000), De Nooy et al. (2005) and Robert and Riddle (2005) also provide interesting insights.
} 
example depicted in Figure 2 is meant only to convey a basic understanding and intuition of the key notions of social network analysis used in the rest of this section.

\section{Figure 2. First example of socio-gram}

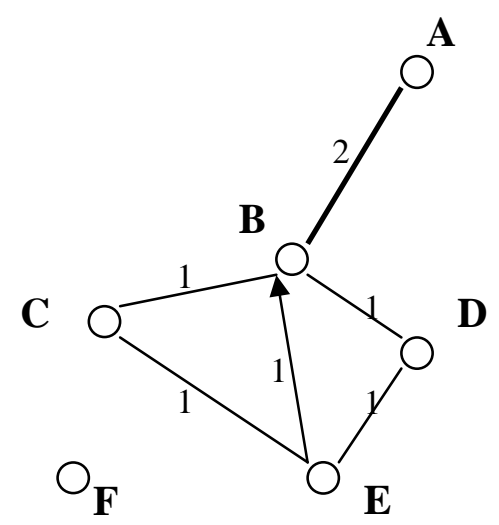

The link between two nodes can be re-presented by an edge (undirected link, e.g. B-D) or by an arc (arrow, directed link E-B), depending on the type of relationship examined, for instance: a common partnership and a knowledge flow, respectively. In the former case, it is a undirected network; in the latter case it is a directed network. This distinction is particularly useful if we want to track the direction of knowledge flows. For example actor $\mathrm{E}$ in Figure 2 can be interpreted as a technician transmitting a piece of knowledge to a colleague (i.e. actor B). It is important to note that actor B does not reciprocate. Thus the outbound arrow from node $\mathrm{E}$ indicates that $\mathrm{E}$ is the net provider of knowledge, and the inbound arrow to node $\mathrm{B}$ indicates that $\mathrm{B}$ is the net receiver. The example shows that reciprocation and mutual relationships can be graphically detected in a directed network. This is particularly useful in studies of informal knowledge trading, where an actor's decision to provide information is based on mutuality. Social network tools enable the visualisation and measurement of these important qualifications of knowledge exchange. ${ }^{11}$ Each link can also be labelled according to its intensity. Tie density captures the strength of a network interconnection. For example, in a network of $R \& D$ alliances, intensity can be measured by the number of alliances signed by two connected organisations (e.g. intensity is 2 between A and B, and 1 between B and D). Interpersonal relations have been differentiated in terms of 'strong' and 'weak' ties (Granovetter, 1973). According to Granovetter (1974) the strength of an interpersonal tie depends on a combination of time, emotional intensity, intimacy and reciprocity between two individuals. Strong ties identify those persons with whom one interacts on a regular basis; weak ties are those with people with whom interactions are sporadic. Weak ties capture relations with people outside one’s daily entourage. In particular, Granovetter (1973) makes the assumption that if an individual (say B) has strong ties with two other persons (say A and

\footnotetext{
${ }^{11}$ For an empirical application of informal knowledge flows see Giuliani and Bell (2005) and Morrison and Rabellotti (2005).
} 
C), then some kind of tie between A and C must exist. This assumption, based on empirical results, has a logical implication: weak ties allow to access only to information circulating in other contexts, i.e. weak ties can only bridge two subsets of a network. Thus, the information they supply is not redundant, implied by the phrase the strength of weak ties. However, there is an important difference between strong and weak ties: strong ties are based on reciprocity and trust, so they tend to reinforce existing relations and perspectives and have been associated with the transmission of complex knowledge (Hansen, 1999; Sorenson et al. 2006). Weak ties serve mainly to access novelties in terms of new ideas; thus they are particularly effective when small amounts of highly codified information are important (e.g. in job searching).

To keep these definitions and examples simple, we refer in the following examples only to undirected and binary valued networks. We therefore do not take account of the direction or intensity of the ties linking pairs of nodes. We refer to directed and/or valued network only where the paper under analysis adopts these descriptions.

Nodes can be connected indirectly via other nodes, e.g. A-D in Figure 2. A path is a sequence of distinct nodes and lines, starting and ending in nodes. For instance, there are three distinct paths connecting A to D: A-B-D; A-B-C-D and A-B-E-C-D. ${ }^{12}$ The length of a path is given by the number of occurrences of lines in it. Coming back to our previous example, the three paths connecting A-D are long - 2, 3 and 4 respectively. The geodesic distance between two nodes is given by the shortest path connecting them, e.g. the geodesic distance between A-D is 2. If there is no path connecting two nodes, the geodesic distance is assumed to be infinite, e.g. the distance between $\mathrm{F}$ and any other nodes of the network.

A component is a subpart of a network in which there is at least one path that links all its nodes. In other words, all nodes within a component have to be reachable in at least in one way. The size of a component is given by the number of its nodes. The component reporting the largest size is termed the giant component. In many actual networks, the majority of nodes belong to a giant component and more sophisticated analyses often focus exclusively on giant components (e.g. Newman 2001). In our socio-gram (Figure 2) example, there are two components: the first, the giant component, is given by $\{\mathrm{A}, \mathrm{B}, \mathrm{C}, \mathrm{D}, \mathrm{E}\}$ and its size is 5 , the second is given by an isolated node, i.e. F, which is a trivial component.

A core concern in the literature is the position occupied by different agents in various types of networks. Network position and, more specifically, network centrality are considered important factors for economic outcomes (e.g. Coleman, 1988; Tsai and Ghosal, 1998). Different network positions offer different opportunities for organisations and individuals to access new knowledge. Being at the core of a network provides greater access to sources of knowledge and greater control over the resources that stem from them. Empirical evidence seems to support this view and it has been argued that the centrality of an organisation is positively related to its innovation performance (e.g. Tsai, 2001). Although there are different ways to

\footnotetext{
${ }^{12}$ One can also pass from A to D following the sequence A-B-C-E-B-D. According to our definition, this is not a path, since it passes through $\mathrm{B}$ twice and is described by the more general term walk.
} 
characterise the position of a node in a network, we limit our discussion to the most common measures of centrality: degree centrality and betweenness centrality.

Figure 3. Second example of socio-gram

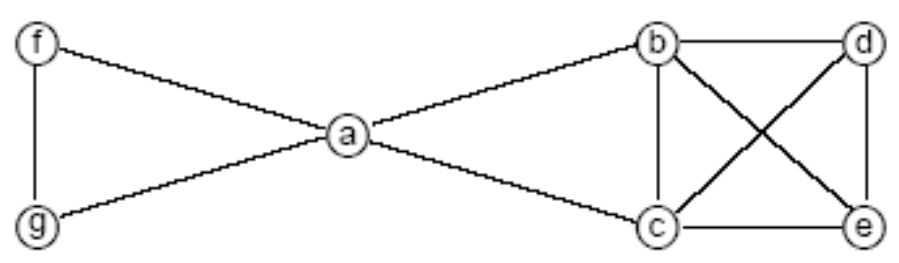

Degree centrality is defined simply as the number of lines incident with a node. For example, in a network where nodes represent organisations, degree centrality is defined as the number of other organisations with which the focal organisation has a relational tie. With reference to the hypothetical network depicted in Figure 3, nodes $a, b$ and $c$ present the highest values of degree centrality being connected to four other organisations.

Betweenness centrality is a measure of the influence that a node has over the spread of information and knowledge throughout the network. The underlying idea is that each node on the information path linking two other nodes is able to exercise control over the flow of knowledge within the network. Formally, betweenness is defined as the fraction of the shortest paths between node pairs that passes through the node of interest. In Figure 3, it is intuitive that node $a$ has strong influence as a network connector. For example, the shortest path between organisations $d$ and $g$ has length 3 and organisation $a$ lies on it. If one takes all possible pairs of organisations (excluding $a$ ) and counts the number of shortest paths connecting them, it can be seen that organisation $a$ lies on 8 out of 15 of them. The betweenness centrality of organisation $a$ is therefore equal to $8 / 15=0.53$. It is therefore highly influential in mediating the knowledge flows taking place among the nodes in the network. By contrast, organisation $b$ lies on only three shortest paths (i.e. those connecting node $d$ with nodes $a, f$ and $g$ ) and therefore has a lower value of betweenness centrality (0.20).

According to the most recent graph-theoretic literature, the following are other important structural properties usually analysed in the empirical literature:

- Number of nodes (economic actors)

- Number of edges (links)

- Density of the network

- Number of components 
- Size of the largest component

- Average degree

- Average distance

- Clustering coefficient.

The density of a network is given by the ratio between the number of actual links and the maximum theoretical number of possible links.

The clustering coefficient of a node is the proportion of links between nodes in its neighbourhood divided by the number of links that could possibly exist between them. The clustering coefficient for the whole network is the average of the clustering coefficient for each node and indicates the level of social capital, since it measures how many direct partners of a specific organisation collaborate with each other.

Given the above structural properties, it is possible to check if a network displays small-world ${ }^{13}$ properties. Any network structure can be classified according to simple two properties: average path length, and average cliquishness (Watts and Strogatz,1998). Average path length is a global concept, defined as the average number of steps separating two randomly chosen agents. Average clustering (or cliquishness) is a local concept, measuring the degree of link redundancy in an agent's neighbourhood. The combination of short path length and high degree of local clustering, in particular, characterises small-world networks in which tightly linked local cliques are connected to each other through a few shortcuts. ${ }^{14}$ Numerous theoretical studies (e.g. Cowan and Jonard, 2004) have shown that the small world is a more effective network structure in terms of diffusion and creation of knowledge.

\subsection{Data and the construction of networks}

Network data focus on actors and relations. We review some studies based on data on relations among economic actors. For example, two individuals can be linked if they exchange know-how, as illustrated in Giuliani and Bell (2005). In some cases, data measure rather different relations, e.g. R\&D alliances (e.g. Gulati and Gargiulo, 1999) or patents (e.g. Breschi and Lissoni, 2006). Data in this case describe ties between two different sets of nodes: they identify linkages connecting economic actors (e.g. organisations, inventors) with events (e.g. $R \& D$ alliances, patents). They are referred to as affiliation data and the corresponding network is described as a two-mode network. Figure 4 provides an example of a two mode network, including six inventors involved in four different patents.

\footnotetext{
${ }^{13}$ The idea of small worlds dates back to Milgram (1967) who demonstrated that a low average distance characterizes most social networks.

${ }^{14}$ Here low path length means that the network has the same value as a random network with the same size and density; high clustering coefficient means that the network has a value that is much greater than the value of the random network.
} 
Figure 4. An example of a two-mode network (Patent data)

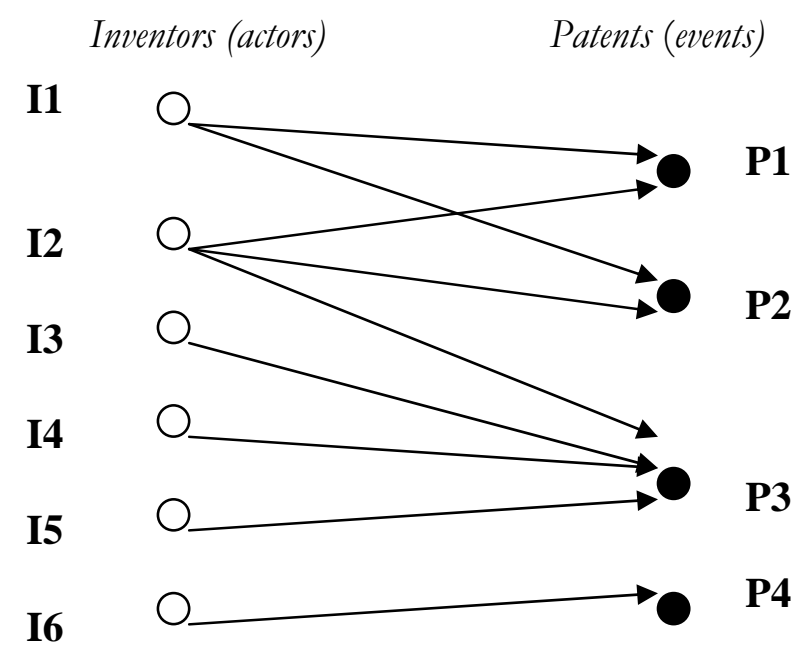

A very common and useful approach to two-mode data is to convert it into a one-mode network, and examine relations within each mode separately. Of course, two different one mode-networks can be built from a two-mode network. For example, it is possible to reconstruct a network of inventors (Figure 5, part A), where ties are given by co-participation in a patent and strength measured by the number of participations (e.g. Breschi and Lissoni, 2006). We can also define a one-mode network in which patents (events) are the nodes (Figure 5, Part B) and common inventors are the ties, coding the strength of the relation as the number of inventors that each pair of patents has in common (e.g. Singh 2005). However, each transformation results in a loss of information, for example in a network of inventors, it is not possible to identify which patent links two individuals, and in networks of patents the identities of the inventors are lost.

Figure 5. Two different one-mode networks derived from the two-mode network of Figure 4

A. Network of inventors

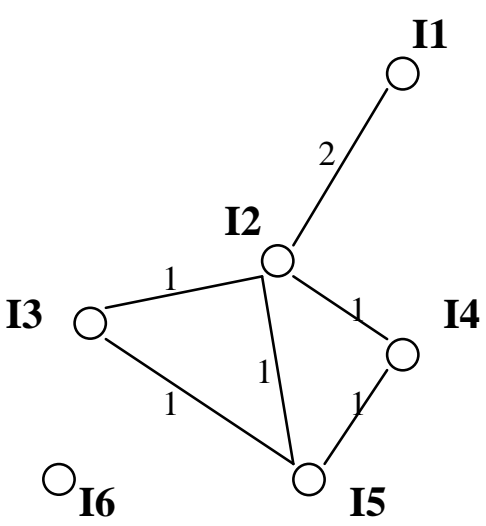

B. Network of patents

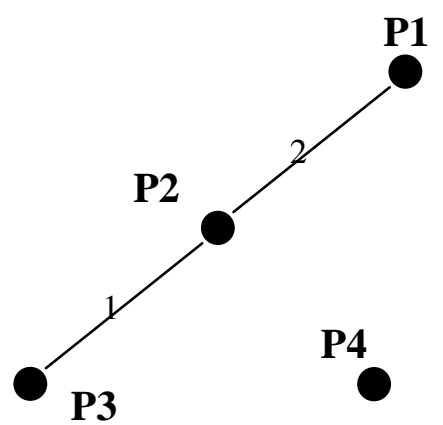


The two graphs in Figure 5 refer to patent data, but the forms would not be very different if R\&D alliance data were considered. However, it is worth noting that, in the case of partnership networks, some studies represent one-mode networks in a rather different way. In particular, Breschi and Cusmano (2004), in a seminal paper dealing with networks of organisations participating in European Framework Programmes (FP), make two different assumptions related to how partnership can work and, therefore, be represented. ${ }^{15}$ Normally, in building partnership networks, partners are assumed to be of equal importance (Figure 6A). However, some datasets, such as the EC Database used by Breschi and Cusmano (2004), allow identification of the Prime contractor (i.e. the Co-ordinator of the activities undertaken within the project) in each R\&D consortium. Thus, taking consideration of the importance of these organisations and given the fact that it is likely that organisations involved in large $R \& D$ consortia know the co-ordinator better than they know each other, an alternative way of representing the one-mode network is a 'star' graph (Figure 6B). Within this hypothesis, Prime contractors would act as intermediaries between partners in the same project, and no direct edges would exist between partners.

Figure 6. Alternative representations of a one mode network

(e.g. four organisations participating in a research project)

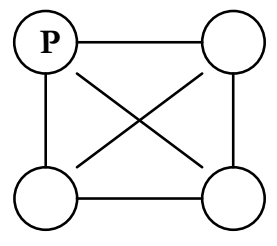

6A. no specific role for $P$ - clique hp

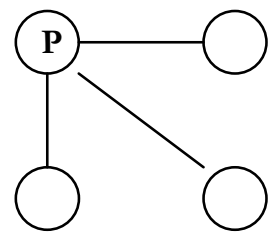

6B. $P$ as coordinating agent - star $h$.

Both representations in Figure 6 are based on strong assumptions about the role of Prime Contractors. The strategy followed by Breschi and Cusmano (2004), and others after them, is to explore the

\footnotetext{
${ }^{15}$ Several studies have followed this approach in assessing the structure of FP networks, e.g. Roediger-Schluga and Barber (2006), Breschi et al. (2007) and Cassi et al. (2007).
} 
main topological characteristics of the network with respect to both hypotheses, in the absence of reasons to adopt either one or the other.

\subsection{Questionnaire data: collection and measurement issues}

Network analysis often requires network data on the relations connecting actors in a given population. ${ }^{16}$ Patent datasets, as discussed above, include all the actors in the population studied (i.e. inventors), and the relations among them (i.e. participation in the same patent). Yet, these kinds of datasets are an exception; very few already existing datasets on innovation related issues include relational data. Gathering relational data is costly and time consuming; a great deal of time and effort is involved in collecting data on large populations. In addition, relational data contain sensitive information about the respondents' personal and professional lives - respondents are often asked to name friends and colleagues with whom they are in contact, and to qualify these relations in terms of intensity, which makes their collection much more difficult.

The above suggests that the most prominent problem encountered in research involving network data lies in defining the boundaries of the population being studied. Large populations are difficult to survey, so most studies, including those reviewed in this work, focus on small groups of individuals/firms. The criteria adopted to specify the boundaries of a community are based primarily on the object/purpose of the analysis. For example, most studies on knowledge flows in industrial clusters set geographic boundaries (e.g. firms and their technicians located in the cluster being investigated). Similarly, studies on collaborations among scientists set the boundaries in terms of knowledge/discipline domains or academic affiliations. Setting the boundaries to a population is particularly important in network studies since analyses focus explicitly on the interactions between the actors in the population studied. Omission or arbitrary specification of these boundaries leads to biases and misleading results (Marsden, 1990). ${ }^{17}$ In terms of data collection, different methodologies can be used including questionnaires, interviews, observations, archival records, experiments, or a mix of all or some of these methods. Questionnaire based surveys are the most widely used method of data collection, often complemented by in-depth interviews with key informants or archival records. Questionnaires ask respondents, for example to indicate from a list, those individuals/organisations with whom she/he has a direct contact. A roster (i.e. list) is a common format in studies of delimited populations; in this case the researcher needs to know all the members in the set prior to data gathering. Free recall is used where the boundaries are not known, i.e. the researcher has to ask respondents to 'name the people with whom you are in contact. Roster and free recall can be used where boundaries are not clearly defined, giving respondents the licence to list all the actors they consider to be relevant sources of information. For example,

\footnotetext{
${ }^{16}$ Sampling methodologies have been elaborated to overcome the problems involved in enumerating all the actors within a population. A comprehensive study on network analysis that deals with the issues covered in this section is Wasserman and Faust (1994).

${ }^{17}$ Population boundaries is a hot issue for network analysis based on existing relational datasets, which have similar problems and pitfalls to those that occur in questionnaire data. Once again, we refer to Wasserman and Faust (1994) for a comprehensive treatment of this issue.
} 
Morrison and Rabellotti (2005), in their study of the Novara (Italy) wine cluster, asked firms' technicians to indicate the main research organisations with whom they collaborated within and outside the cluster. A preliminary list of local organisations (e.g. universities, agriculture colleges, branches of international organisations) and the main national and international ones was provided, but respondents were allowed to add any other contacts not included in this list. The format used can be closed or free choice: i.e. respondents can be free to report as many linkages as they want, or can be asked to specify a maximum number of linkages. Usually, additional questions are included in order to specify the type/features of linkages. For example, studies on informal knowledge flows, such as those reviewed here, ask respondents to specify the intensity of the relation either in terms of frequency or in terms of contribution to the solution of a given problem. Below are examples of two questions, formulated respectively in Giuliani (2007: 150) and Morrison and Rabellotti (2005: 10):

If you are in a critical situation and need technical advice, to which of the local firms mentioned in the roster do you turn?

[Please, rate the importance you attach to the knowledge linkage established with each of the firms according to its persistence and quality, on the basis of the following scale: 01/4none; 11/4low; 21/4medium; 31/4high].

Do you have any informal contact with employees - or the owner - of the following firms (see the list) aimed at exchanging information (about business opportunities; markets; providers; inputs; machineries or technologies)?

[Please indicate the frequency of such interaction [none $=0$; occasional $=1$; frequent (every month) $=2$; highly frequent (weekly) $=3$ ].

These examples show that linkages can also be rated according to a scale (e.g. low, medium, high). In studies of knowledge flows, rating is often used to assess the contribution of a specific link to the solution of a complex technical problem.

The methods and formats briefly reviewed above are not exempt from problems. Issues of accuracy, reliability and sensitivity are common in the collection methods discussed above. The key problem is that there is a discrepancy between the observed structure reproduced using network data and the true structure of relations (Holland and Leinhardt, 1973, quoted in Wasserman and Faust, 1994: 56). Thus several measurement errors may arise. In studies dealing with questionnaire data accuracy problems often arise, since most network data are collected through self-reporting questionnaires. Research in this field suggests that individuals are not very good at recalling their interactions, especially if they were in the distant past. However, there is also evidence that suggests that this does not constitute a major problem since researchers are interested in stable patterns of interactions, which are those that respondents tend to report more frequently when responding to questionnaires (see Wasserman and Faust, 1994: 57). An important issue related to accuracy concerns the discrepancy between the type of actor under analysis (e.g. formal organisation) and the sources of the information on linkages, which in most studies - including those reviewed in this work - is individuals. In this case, we should assume that the informants know all the relevant collaborations/relations of their firms. 


\section{INTER-ORGANISATIONAL NETWORKS, KNOWLEDGE TRANSFERS AND INNOVATION}

\subsection{Informal knowledge flows}

The role of informal contacts in knowledge transfers and in fostering innovation, has been widely debated by scholars in economics and related fields. There are two different streams of literature on this topic: on the one hand scholars in the fields of regional economics and economic geography have attempted primarily to asses the role of territories and the institutions therein, in affecting the spatial diffusion of knowledge (Audretsch and Feldman 1996; Becattini, 1990; Boschma and ter Wal, 2006; Brusco, 1996; Camagni, 1991; Capello, 1999; Feldman, 1999; Keeble and Wilkinson, 1999; Rallet and Torre, 2005; Sabel et al., 1987; Saxenian, 1994); on the other hand a number of contributors in the field of innovation and organisational studies have examined the micro dynamics of learning within and between organisations (Breschi and Lissoni, 2001a and b; Schrader, 1991; Giuliani and Bell, 2005; Giuliani, 2007; Lissoni, 2001; Lissoni and Pagani, 2003; Morrison and Rabellotti, 2005; von Hippel, 1987).

Both approaches underline the importance of personal, face-to-face interactions as channels for knowledge transfer. This argument is rooted in the basic properties of knowledge, which is assumed to be idiosyncratic, contextual, sticky and tacit (Polanyi, 1962 and 1967). Given that knowledge is embodied in the skills of individuals, personal interactions and therefore local embeddedness are key factors for enhancing knowledge sharing and collective learning. 
Regional studies stress the importance of physical proximity as a key factor for knowledge transmission. A few econometric works, particularly in the context of industry-university relations in the US (Audretsch and Feldman, 1996), have provided strong support for the existence of a positive relationship between spatial clustering, localised knowledge spillovers and firms' innovative output. The presence of local knowledge spillovers from universities and research laboratories would explain why firms tend to colocate, and informal relations between the employees in those organisations are identified as a key mechanism for tacit knowledge transmission.

A more traditional approach in the field of regional studies criticises this interpretation of space and focuses on institutional and cultural factors. A number of contributions refer to the concept of innovative milieu to account for the learning processes that occur at local and network level (Camagni, 1991; Capello, 1999; Keeble and Wilkinson, 1999; Rallet and Torre, 2005). In this context, learning is seen as a collective and social process involving people who share strong social and cultural values. Informal relations within the milieu, along with other mechanisms (e.g. spin-offs; labour mobility; user-producer interactions), contribute to sustaining the diffusion of knowledge at the local level, which is regarded as a club good within cluster boundaries (Capello and Faggian, 2005). This approach clearly makes the point that not only firms' geographical proximity, but also their embeddedness in a specific milieu affect the process of innovation in clusters.

Overall perhaps, studies on industrial districts and craft industries (Sabel et al., 1987; Becattini, 1990; Brusco, 1982), though not directly investigating the link between informal ties and innovation, have provided the most notable examples of socially embedded industrial relations, in which informal ties, along with formal inter-organisational networks, have proved to be effective in enhancing knowledge production, diffusion and growth. There is the case of the German textile industry described by Sabel et al. (1987), in which SMEs are inserted into a thick web of vocational schools, research institutes and specialist services. This environment enables them to specialise along the value chain and build large and stable networks of subcontractors, which favours cooperative behaviour and reinforces the social structure in which the firms are embedded. A further remarkable case is that of the so-called Third Italy, in particular the well-known Emilia-Romagna model of production analysed by, among others, Brusco (1982) and Lazerson (1988). The most distinctive feature of this model is the presence of a unique set of political, cultural and social institutions, which enable trust, cooperation and social commitment, and enable workers to undertake new entrepreneurial activities (e.g. spin-offs) and technicians to access new pieces of knowledge by exploiting their social linkages. Overall, the local community acts as a social glue and provides a vast array of tangible and intangible resources that its members can exploit to produce new products and ideas at a faster rate than in other organisational contexts (e.g. vertically integrated firms).

A similar pattern of interaction and trust based relationships has been observed in the context of Silicon Valley, discussed by Saxenian (1994). She describes the functioning of technical communities of engineers, which are loose groups engaged in similar activities, and which although working in different and 
often competing firms, have the same technical problems and generally have common views on how to conduct research. Saxenian observed that informal interaction and conversation among technicians was common and was encouraged by firms, and suggested that "this decentralised and fluid environment accelerated the diffusion of technological capabilities and know-how within the region” (p. 37). Other studies support the view that informal ties within and between different professional groups, associations and academics in Silicon Valley-type contexts have a major impact on the rate of growth of ideas and on technical change more broadly (Cohen and Fields, 1999; Kreiner and Schultz, 1993).

The focus of innovation studies has been on knowledge generating and sharing processes occurring at the micro level (e.g. firms, R\&D departments). A prominent example of informal networks is von Hippel's (1987) work on know-how trading among US steel mini-mill producers (a detailed analysis of this work is provided in the next section). This and other contributions (Carter, 1989; Dahl and Pedersen, 2004; Schrader, 1991; Lissoni, 2001), show that exchange of proprietary knowledge is commonplace among technicians of competing firms. This is because technicians feel they are part of a cohesive professional community, in which reputation and status shape interactions. These exchanges take the form of trading, meaning that technicians are willing to provide critical information on the basis of reciprocity (Schrader, 1991; von Hippel, 1987). This implies that knowledge is not given for free, but is exchanged through barter, the preconditions for which are trust, mutual recognition and long-term relationships (Carter, 1989). These studies show that trading in know-how contributes to solving technical problems which increases firms' productivity.

Some recent research has reappraised the part played by informal networks in knowledge diffusion, with special attention to the geography of knowledge flows and innovation (Breschi and Lissoni, 2001a and b). These scholars are critical of the well established arguments on local knowledge spillovers: first, the idea that face-to-face contacts, that is personal contacts in space, are per se the key channel through which knowledge (for innovation) circulates; second, the belief that physical proximity implies the existence of social networks, which in turn implies that simple co-location with a knowledge source is sufficient for accruing the benefits of knowledge spillovers. Breschi and Lissoni (2001a: 977) argue that the knowledge spillovers concept is a sort of black box, "an unequivocal summary variable for a number of knowledge flows, each of them being diffused, at closer look, by its own specific transmission mean”. They suggest that, in order to understand the role of informal networks in enhancing knowledge sharing, future research should investigate in more detail the identity of actors (e.g. individual firms, inventors, professionals), the nature of knowledge and the transmission mechanisms.

This line of research has had an impact on the literature in terms of re-setting the priorities of the research agenda. For example, in the most recent contributions in the field the focus has shifted from the measurement of knowledge spillovers in informal networks to identification of the relevant community of actors and the relevant type of knowledge. More importantly perhaps, this reappraisal has had a major impact on the research methodology adopted in empirical studies. Scholars tend to adopt the more conventional, 
more conservative, production function approach to measuring knowledge flows, while more accurate measures, based on social network analysis, have been computed to track the movements of professionals and researchers. Relational indicators are increasingly diffused, not only in innovation studies, but also in regional approaches, to investigate the role of actors' positions in knowledge diffusion and informal network structures as a whole have been assessed to determine the optimal configuration for accessing information and knowledge.

In sum, regional economics and innovation studies have increasingly incorporated a network approach to study informal knowledge flows. We discuss a selected sample of the most relevant empirical studies on informal networks in the following next two sections. The first focuses on investigations based on case studies and questionnaire data, and the second looks at analyses based on existing datasets (e.g. patents).

\subsubsection{Case studies and survey data}

Relatively few empirical studies link informal networks to knowledge flows, and even fewer explicitly incorporate social network analysis in their empirical investigations. In this section we review some studies based on case-study methodology and questionnaire data.

\section{Case studies}

The first group of works (Carter, 1989; Schrader, 1991) draws on von Hippel's (1987) seminal paper. These contributions adopt a firm level case-study methodology in a specific industry. All are based on in-depth interviews with plant managers and other engineers who are very knowledgeable about their firms' manufacturing processes. This method of inquiry ensures that the community of actors that are potentially involved in informal knowledge networks is identified and adopting a sectoral perspective allows the specific nature of knowledge to be acknowledged - in terms of complexity, transferability, codifiability, appropriability, etc. - and how actors deal with it in their activities.

These authors found that the sharing proprietary information and know-how with peers in both allied and rival firms is commonplace. Exchanges occur outside of any formal collaboration arrangements and are not driven by market mechanisms (i.e. price). Informal know-how trading can take the form of technical assistance or requests to peers for information to solve on the job problems. Thus, for example, an engineer might ask the help of a colleague working in another firm with experience of similar problems or with the skills and competences required to resolve the problems. Thus, exchange works as a barter, in which the decision to provide assistance is based on a cost and benefit assessment, the cost being the time and effort 
devoted by one party weighted against the potential help she may receive in the future. The public nature (difficulty in defining price; uselessness of duplication; non rivalry in consumption) of the goods traded (i.e. information and know how) makes barter an effective mechanism for exchange, where the balance between what is given and received is reached in the long run; contemporaneous barter is a much rarer event.

Concerning the benefits and costs of knowledge exchange, while the former are associated with the possibility of asking for help in future, the latter, described in the literature as the cost of "competitive backlash”, is the reduction in the rent pertaining to that piece of knowledge. In this context, Schrader (1991) identifies three main factors affecting competitive backlash: the degree of competition; the availability of alternative sources of information; the knowledge domain of the information traded. The higher the degree of competition between firms, the higher will be the cost of transmitting information based on losses in terms of rent. If several other sources of information exist, the corresponding cost of realising that given piece of knowledge will be low, since the rent would be eroded in any case. Finally, know-how trading is more likely to occur if it involves knowledge domains that do not constitute key sources of competitive advantage. Based on a sample of 294 technically-oriented middle level managers in the US specialty steel and mini-mill industry, Schrader (1991) found that there was a negative effect of competition and the positive effect of the existence of alternative sources of information, on the probability of information being revealed to other firms.

More importantly, these studies show that in informal knowledge networks, social relations (e.g. friendships) play a central role since reciprocation is based on trust, which is built and nurtured though social interactions. Therefore social networks matter, since they serve to identify pairs of agents engaged in knowledge exchanges, or in other words, an engineer's social networks delimit the set of agents she can turn to in search of useful advice. Since know-how trading is based on trust and reputation, social connections cannot be formed strategically for the purpose of finding solutions to particular problems: an engineer must choose which person in her social neighbourhood is the most appropriate to ask for help. In particular Schrader (1991), while finding that friendship does not have a significant effect on the probability of information trading, suggests that friendship or acquaintance may delimit the community in which information can be exchanged (for a more detailed discussion on the boundaries of the social community see section 5).

In sum, the case studies reviewed above seem to show that know-how trading has some recurrent specificities in terms of both content and modality of exchange. The three main ones are: (i) exchange of knowledge, which works as barter; (ii) effective exchange, which depends on comparing the benefits and costs to the employing firm; (iii) exchange that occurs between socially connected individuals.

\section{Questionnaire data}

Recent contributions in this group include Lissoni (2001) and Lissoni and Pagani (2003), which investigate knowledge codification and diffusion processes in the mechanical cluster of Brescia, a highly 
performing cluster located in the North of Italy. The empirical analyses are based on a mix of qualitativequantitative interviews and structured questionnaires involving engineers working in the most representative firms in the cluster. The sample includes firms active in the key sectors of the operating machine industry (textile machinery, metalworking machine tools, plastic-processing machinery) and its subfield (hosiery machinery, metal moulding presses, moulding presses for thermoplastics). It should be stressed that as pointed out by the authors, the strength of the research rests in the detailed reproduction of the different stages of production and design work-flow provided for each firm in the sample. This is based on the lengthy and in-depth interviews with key engineers engaged in prototyping, design and testing activities, which among other things provides some familiarity with the terminology and jargon used by technical staff. Moreover, they helped the authors to identify the competencies and knowledge of the people engaged specific activities and allowed them to define accurately the nature (in terms of tacit-codified distinction) and relevance of the knowledge used in these processes.

Lissoni and Pagani are somewhat sceptical about the role informal networks in channelling relevant knowledge, i.e. the types of technical information that is useful for developing commercial innovations.

Results from a survey of 200 engineers support this view: only 36\% of those interviewed reported interacting with peers in other firms. Less than $18 \%$ had conversations with employees from other firms on technical topics, and only a few (4.5\%) had discussions about on-going projects. In addition, the extent of social ties appeared rather limited with only $21 \%$ of respondents in the sample have strong friendship or kinship ties. Thus, Lissoni and Pagani’s findings seem to suggest that where informal networks exist, the consist of weak ties, which allow generic information (e.g. about new technologies) to diffuse readily, while key pieces of knowledge seem to be appropriated by firm-centred networks. A different picture emerges if we look at vertical relationships between users and producers of machines. Lissoni finds that engineers in machine manufacturing firms and test customers (users) interact on a regular basis. These contacts are mainly informal and serve to provide feedback and introduce modifications to machines. However, although these types of networks are not formally regulated, informal contacts seem to "arise from successful commercial partnerships and deals, and respect firms' appropriations strategies” (Lissoni, 2001: 1498), which suggests that firm boundaries matter a great deal when critical information is involved.

Dahl and Pedersen (2004) analysed the importance of informal ties by means of a survey submitted to 791 engineers working in 19 firms belonging to NorCom, a formal association of firms located in a wireless communications cluster in North Denmark. The main survey information concerns engineers' work experience, competences, relations with engineers from other firms, contact with university researchers, importance of contacts (in terms of knowledge acquired), basis of contacts. The main purpose of the study was to assess whether valuable knowledge circulates within communities of engineers in geographically bounded areas. In other words, the authors were testing the role of inter-firm informal networks in transmitting knowledge locally. The results confirmed most of their predictions: that knowledge flows through informal contacts do take place, $76 \%$ of respondents had contacted at least one employee in another 
firm in the cluster and $41 \%$ had obtained some kind of knowledge through this interaction. Contrary to Lissoni's findings, these exchanges were concerned with specific information: 30\% of respondents reported accessing technical information about new products and $60 \%$ of them rated the knowledge acquired as being of high/medium value. This study also found that engineers do acquire knowledge through social ties and rated this knowledge as of medium importance to their day-to-day work. More than $50 \%$ of respondents reported having established contacts with former classmates and $66 \%$ were in touch with former colleagues. The percentage of friends involved in knowledge networks was also significant: $47 \%$ of respondents acquired information through friendship ties.

Besides social ties, informal networks can be based on previous formal collaboration between the firms in which engineers are employed. Research shows that previous involvement in formal projects increases the probability of establishing informal contacts. However, as already indicated, some firms try to prevent knowledge sharing (von Hippel, 1987; Schrader, 1991). Some firms, often multinationals that are newcomers to a cluster, introduce competition rules that restrict engineers from exchanging knowledge deemed to be critical for the firm. Although only $16.2 \%$ of respondents reported being subject to any such constraints, they do exist and can significantly reduce the intensity of engineers' interactions.

These two case studies seem to indicate that effective informal know-how trading is mainly affected by (i) the type of knowledge exchanged, and (ii) the strategy of the firms. Any analysis needs to take account of sectoral, or even idiosyncratic aspects.

\section{Questionnaire data with social network analysis}

Based on results of case studies looming at the importance of social networks, some scholars have tried to apply social network tools to measure the link between informal networks and knowledge diffusion/innovation. Graph theory has been widely applied to provide a clear visualisation of the connections linking actors engaged in knowledge trading and to qualify the nature and content of these ties (e.g. strong vs. weak; temporary vs. stable).

A notable example here is the paper by Giuliani and Bell (2005), which investigate a Chilean wine cluster using relational data obtained from interview-based questionnaires administered to technical employees (oenologists) in 32 wine producers. The authors' empirical aims were to: analyse intra-cluster knowledge flows and how they are related to a firm's cognitive position; assess the importance of extra cluster linkages to access knowledge; test whether a firm's position in the knowledge network is related to firm-specific characteristics (e.g. absorptive capacity). In particular they predicted that informal networks are more likely to be established between firms with stronger knowledge assets. The greater the firm's knowledge base the more central will be its position in the informal knowledge network. The predictions were generally confirmed by the empirical analysis. They found a positive correlation between a firm's centrality in the knowledge network and its absorptive capacity. The more firms know, the more they act as sources of knowledge for other firms in the cluster, while those with weak knowledge bases tend to be 
cognitively isolated. Therefore, different heterogeneous subgroups of relatively homogenous actors appear in the cluster. More specifically there is a core-periphery structure (Borgatti and Everett, 1999). This particular network configuration consists of two different groups of actors: a highly connected group of firms (i.e. the core), which exchange knowledge actively among themselves, but are loosely connected with the periphery; and a periphery, which is formed by firms that are loosely connected with the core, and have very few connections among themselves.

Similar to the know-how trading literature, knowledge is defined here in terms of technical advice, the practical know-how that technicians get from their peers in order to cope with complex problems. The paper by Giuliani and Bell (2005) however does not take in account one central issue: i.e. the genesis of informal relations. In contrast with the studies reviewed above, the survey in this study focuses exclusively on cognitive aspects, which seem to be the only factor relevant to why a pair of actors establishes a link (for more details see next section). In addition, little is known about the extent to which firms restrict their employees' external contacts. This is partly due to some ambiguities in the definition of the unit of analysis used by Giuliani and Bell. They surveyed key technicians in each firm in the population, which specified their personal network of contacts, yet analyses and results are interpreted in terms of inter-firm relations. This may give rise to problem of accuracy, a more detailed discussion on this methodological point is provided in section 3.3 .

Boschma and ter Wal (2006) studied the footwear cluster of Barletta in the South of Italy. Drawing on Giuliani and Bell's (2005) methodology they tested whether firms' positions in the knowledge and market networks were related to firm-specific characteristics (absorptive capacity, innovative performance, economic performance). Like Giuliani and Bell (2005) they found that knowledge flows where firms reported having given or received 'technical support' in terms of market or technical knowledge. They found that a firm's position in the knowledge network positively and significantly affects its innovation performance. Moreover a firm's network position is influenced by its absorptive capacity. Clustered firms do not form a giant component, many are disconnected, and these are generally weak performers, which also suggests that co-location in the cluster does not provide immediate access to knowledge spillovers. As was the case with Giuliani and Bell (2005), how the linkages connecting actors were established is not explored. Other studies have employed network analysis to disentangle the different types of knowledge exchanged through informal networks. Morrison and Rabellotti (2005) and Giuliani (2007) explore this issue in the context of wine clusters. The former study is based on a survey of 26 oenologists and viticulturists working for wineries in a small wine cluster in a Northern Italian province. The latter, drawing on Giuliani and Bell (2005), compares three wine clusters located in Italy and Chile. Overall they argue that informal conversations transfer technical knowledge; however, this channel can also be used to share information about job opportunities; to get information about markets trends, machine performance, new inputs, new regulations (Granovetter 1973; Stuart and Sorenson, 2003). Therefore informal contacts in professionals 
groups are built for different purposes; they respond to different motivations and accordingly are likely to show rather different network structures.

Morrison and Rabellotti assess whether informal contacts serve as vehicles for both know how (firmspecific knowledge) and know what (i.e. generic information). In line with Lissoni (2001), they find that know-how trading is limited to a few actors, while information circulates very freely in the local community, giving rise to dense networks. Knowledge, not surprisingly, is bounded in small communities of technicians. Moreover, findings show that information networks are based on non-reciprocal ties, while actors in knowledge networks are connected through mutual and strong ties. Similarly, Giuliani (2007) finds statistically significant differences between business and knowledge networks, the former being very dense and evenly distributed, and the latter selective, uneven and restricted to a few firms. The differences between different types of knowledge are emphasised by Boschma and ter Wal (2006), who distinguish between market and technical information. Their results confirm that networks differ in strength and density, with market informal networks being much more pervasive than technical ones.

Concerning the importance of social relations in knowledge exchange, the literature provides contrasting evidence. Based on qualitative interviews Schrader (1991) suggests that social ties matter in knowledge transfers; respondents in this study indicated interacting mostly with close friends. However, inferential analysis did not support this view showing no significant effect of social variables on the decision about whether to provide requested information to colleagues. It should be stressed that this latter finding is not to downplay the role of social ties, conversely, as Schrader points out, if taken together with the results of the qualitative interviews, it suggest that social ties matter in defining the community of professionals and colleagues in which information is exchanged. However, “once the network is established and once a person has created the need for a transfer decision by asking a colleague for information, ..., friendship has little impact on the transfer decision” (Schrader, 1991: 167). This view is supported by Dahl and Pedersen's study, but Lissoni seems to reach the opposite conclusion. In his study social relations matter to some extent (18\% of exchanges occur through strong ties), however the key links, those through which relevant knowledge circulates, are among the firm's technicians and its main customers. In this context, social network structure seems not to play a major role in shaping individual's action.

Network analysis and graph theory appear to be powerful tools in defining knowledge flows. It is not entirely evident that social networks matter in shaping individual actions. However, they seem to be important in setting the boundaries of the communities in which information and knowledge are eventually shared.

\subsubsection{Informal knowledge flows and database analysis}

More or less contemporaneously with studies of social and knowledge networks based on questionnaire data, a stream of studies has emerged that analyses conventional datasets (e.g. patent data) as relational data and adopts the social network perspective to explain informal knowledge flows among 
organisations. Breschi and Lissoni, complementing their research agenda set in their papers on localised knowledge spillovers (2001a and b), have developed a methodology using patent data for analysing how social relations determine knowledge flows. This seminal paper (Breschi and Lissoni 2006) ${ }^{18}$ for the first time and in a systematic way uses the list of inventors reported in a patent application document as relational data. ${ }^{19}$ Starting with this information, they build a network of inventors (see Section 3.2 for technicalities) and use this to explain knowledge flows among organisations. This approach was adopted by several others (e.g. Breschi and Lissoni, 2004; Singh 2005; Fleeming and Frenken 2006). Other studies (e.g. Cantner and Graf, 2006) in this line of research use networks of inventors to reproduce inter-organisational networks (see section 4.2 ).

The main aim of Breschi and Lissoni’s (2006) paper is to refine Jaffe, Trajtenberg and Henderson's (1993) analysis of localised knowledge spillovers and to develop a new interpretation of knowledge spillovers based on social rather than geographic proximity. In their 1993 article, Jaffe and co-authors use patent citations to track knowledge spillovers. In particular they analyse the probability that a patent citation occurs between two patents localised in the same geographic area. ${ }^{20}$ Breschi and Lissoni apply the Jaffe et al.'s econometrics exercise to a social space such as that described by a network of inventors. ${ }^{21}$ For each pair of patents (i.e. citing patent/cited patent or control patent/cited patent) they calculate the social ${ }^{22}$ as well as the geographical distance. Results show that social connections are the determinants of co-localisation and conversely that geographical distance loses much of its explanatory power. In particular, they find that the mobility of inventors is the main determinant of citations, which confirms previous results obtained using different methods (e.g. Almeida and Kogut, 1999; Stolpe 2002).

Breschi and Lissoni (2004) and Singh (2005) move a step forward in that both papers analyse the determinants of a citation in terms of social relations, though they do so in slightly different ways and their aims are rather different. Breschi and Lissoni's objective is to show the role of social relations in explaining patent citation patterns among organisations, while Singh's aim is estimate how much of the empirical pattern of citations can be explained simply by the fact that people within a region or within a firm have close interpersonal ties. Breschi and Lissoni focus their analysis on informal knowledge flows among

\footnotetext{
${ }^{18}$ This paper appeared first as a working paper in March 2003 (CESPRI WP series n. 142) and is explicitly cited by Singh (2005) and Breschi and Lissoni (2004).

${ }^{19}$ Indeed, Stolpe (2002) in his analysis of patent citation patterns within Liquid Crystal Display technologies, refers to some social variables measuring mutual acquaintance between two inventors. However, he does not consider the whole network and does not investigate the effect of social relations with a geodesic distance greater than 1 .

${ }^{20}$ The methodological problem they have to address is to isolate the pure spillover effect from other agglomeration effects (e.g. the observed citation could occur between two co-localised organisations simply because all the organisations active in that technological field are located in the same area). They manage to do so by building a control sample of patents that could have been the effective citing patent, but they were not. This control sample needs to be as similar as possible (in terms of technological field and time of application) to the actual citing group of patents. For a critical assessment of this sampling criterion see Thompson and Fox-Kean (2005).

${ }^{21}$ Also the data are different, Jaffe et al. use USPTO data and refer to patents with inventors located in the US; Breschi and Lissoni use EPO data and refer to Italian patents.

${ }^{22}$ Social distance is defined as the lowest among the geodesic paths connecting the inventors of the teams responsible for the two patents.
} 
organisations explained in terms of social relations, while Singh examines interpersonal knowledge exchange and its social determinants.

Breschi and Lissoni (2004), strictly adhering to the methodology they developed in a previous paper (2006), build up a network of inventors, in which inventors are the nodes and co-participation in the same patent activity defines the edges. They analyse how social distance determines the pattern of citations in different organisations. ${ }^{23}$ The social distance between two patents is given by the lowest geodesic distance among the inventors of the two patents. Thus, if an inventor is involved in both patents, the social distance between the two is equal to zero and this inventor is labelled a mobile (or cross-firm) inventor. ${ }^{24} \mathrm{~A}$ social distance greater than zero implies a degree of acquaintance among the two teams of inventors (e.g. distance equal to 1 means that two individuals have been colleagues; distance equal 2 means that they have been colleagues of colleagues). First, Breschi and Lissoni show that although spatial proximity is an important mediating factor, spatial co-location is not a necessary condition for the effective transfer of knowledge: being part of a socially connected group of individuals may indeed help to overcome geographic boundaries. Second, the probability of citations falls quite sharply with social distance. In other words, mobile inventors are greatly influence knowledge flows between organisations and direct or indirect acquaintance opens channels for inter-firm knowledge diffusion, which are probably more effective than geographical colocation per se. Finally, for unconnected pairs, spatial co-location is shown to matter.

Singh (2005) adopts a different research strategy to Breschi and Lissoni (2006). He is not interested in analysing the role of mobile inventors; his focus is on interpersonal knowledge exchanges. He constructs a network, where nodes are teams of inventors (i.e. patents) and the edges are common inventors. He calculates social distance differently from Breschi and Lissoni as being given by the number of nodes existing along the lowest path connecting two nodes. i.e. by definition, two nodes that are directly connected have a common inventor and their social distance is therefore equal to zero. Building the network in this way does not allow cross-firm networks to be identified, and information on mobility is lost. Singh's findings however show that connectedness leads to a higher probability of citation and that the probability of citations decreases as the social distance between pairs of patents increases. Finally, his study shows that accounting for collaborative ties diminishes the results for localised as well as intra-firm knowledge flows.

Fleeming and Frenken (2006) analyse the dynamics in the formation of an inventors' network at regional level, by comparing Silicon Valley and the Boston region. ${ }^{25}$ Unlike the studies reviewed above, their aim is to explain the regional dynamics of informal collaboration by analysing the dynamics of networks of inventors. In particular, they try to explain the strikingly different patterns of evolution in the two regions. The Silicon Valley giant component increases dramatically after 1995: a great number of different small components come together (i.e. they become connected). There is no similar pattern for the

\footnotetext{
${ }^{23}$ Self-citations (i.e. citations organisations make to their own patents) are excluded.

${ }^{24}$ Since self-citations are excluded, the pairs of patents considered by definition belong to different organisations. Therefore, distance zero necessarily indicates a case of mobility, i.e. an inventor working for two different organisations.

${ }^{25}$ They use USPTO data, considering patents of all technological classes applied for in the period 1975-2002 with at least one inventor living in one of the two considered regions.
} 
Boston area. Also, Silicon Valley displays lower average distance, although the giant component is greater. Fleeming and Frenken look for likely explanations but do not find one that is robust. They consider the following possible explanations: open science attitude (they check for the involvement of universities, in terms of number of patents); propensity to collaborate (they check number of inventors per patent), interorganisational collaborations (they check number of assignees per patent) and labour mobility (they consider the ratio between patent holders and patents from new assignees and number of unique inventors in a region). None of these checks show any significant differences between the two regions. In a bid to find a convincing explanation, they supplemented the quantitative results with qualitative evidence from interviews with organisations in the clusters to try to identify idiosyncratic elements. Social network analysis is a powerful tool in this context, since it enables identification of the key organisations to be contacted and interviewed. The interviews revealed that university and private post-doc programmes were significant for both Silicon Valley and the Boston area, but what was peculiar to Silicon Valley was IBM's post-doc programme, which was running during the $1980 \mathrm{~s}^{26}$

In summary, the above studies show that use of co-inventions data to map social relations and to explain knowledge flows can be powerful. This review suggests that a better understanding of the role of social proximity vis a vis geographical distance is needed. In particular, this would help to shed light on the role of labour mobility as a knowledge transfer mechanism. Overall, the results show that (i) social relations are a significant explanation of knowledge flows between individuals and organisations, and (ii) that their explanatory power decreases dramatically as social distance increases.

\subsection{Formal knowledge flows}

The motivations for firms to enter into research collaborations have been thoroughly examined, especially by business scholars (see Hagedoorn 1993, for references to the relevant theoretical literature). Among the reasons identified, a few emerge as being prominent and particularly the search for technological complementarities, the competitive pressures deriving from a shorter product life cycle and reduction in the innovation time-span (i.e. the period between discovery and introduction into the market).

The most recent literature, however, has moved away from the question of why firms enter into alliances to the question of which firms enter alliances and whom they choose as partners (Gulati, 1999). This

\footnotetext{
26 "During that time, IBM's Almaden Lab hired post-docs straight from school-mainly from within the region and especially Stanford-with the intention that they would leave for employment with another private firm after one or two years. The program served three strategic purposes for IBM. First, the post-docs worked for low salaries. Second, there was the perception of value in new people with fresh ideas. Third, the firm assumed that such people would come in and then go away as ambassadors for the firm. It was the latter objective-to seed the technological community with more experienced, IBM-friendly scientists-that catalyzed the formation of large networks in Silicon Valley, as this process created many ties between IBM and many other firms. In other words, the postdoctoral program jump-started a process of network aggregation. Unlike the departure of senior inventors from large and established firms for start-ups (which does not create ties between large components), the post-docs found future employment across a variety of firms. Hence, the IBM postdoctoral program played a crucial role in the initial and continuing aggregation processes in the Valley because it linked large components to other large components” (Fleeming and Frenken, 2006, p. 16).
} 
change in the focus of the research agenda has been inspired by the increasing perception that the search for technological complementarities and strategic interdependence may not be the only factors influencing the choice of companies to engage in research collaboration. In other words, conditions of mutual economic advantage are necessary, but not sufficient for the formation of a research alliance.

A recent set of studies has focused on the dyad level (i.e. pairs of organisations), in an attempt to identify factors that might explain the probability of an agreement and the mode of collaboration. The main dependent variable in these studies is a binary outcome which takes the value 1 whenever two companies form a research alliance, and zero otherwise. Typically, this type of statistical analysis involves taking all the pairs of organisations corresponding to actual research alliances and a sample of pairs that do not. The former are coded as $1 \mathrm{~s}$, the latter as zeros.

The literature has developed mainly along two different (not exclusive) arguments: one related to technologically complementarities (e.g. Stuart 1998, Okanamura and Vonortas, forthcoming), the other referring explicitly to social network mechanisms. One result that is quite robust in this latter stream of literature is that firms tend to form alliances with previous partners (Gulati, 1995a; Gulati and Gargiulo, 1999, Okamura and Vonortas, forthcoming).

Technological alliances are usually complex arrangements in which uncertainty and investment appropriability are relevant. According to this group of studies, prior alliances are useful sources of reliable information. They can provide access to information concerning the competences and needs of potential partners (Gulati, 1995b): “An organisation that knows about the competencies and needs of potential partners is in a better position to assess whether the alliance can simultaneously serve its own needs and its partner's needs. ... Accurate information ... may be difficult to obtain .... [I]t may require access to confidential information that would not be revealed outside an established partnership” (Gulati and Gargiulo, 1999, p. 1442). In addition, previous partners can provide information about the reliability of potential partners. In many transactions, there can be a risk of opportunistic behaviour and therefore trust between partners is important (Gulati and Gargiulo, 1999, Okamura and Vonortas, forthcoming). Firms with experience of working together build trust, which lowers transaction costs and limits the risk of opportunistic behaviour (Gulati, 1995b).

These studies build and analyse partnership networks using R\&D alliance data. They assume that if two organisations participate in the same project they are directly linked, i.e. a one-mode network is built up in which the organisations are the nodes and co-participation is the edges. Since the aim of these studies is to explain what determines the probability of two firms establishing a new link, the explanatory variables is the dyad, i.e. the pair of firms. ${ }^{27}$

In addition, different measures of embeddedness are conceptualised and measured. For instance, Gulati and Gargiulo (1999) refer to three different kinds of embeddedness. First, relational embeddedness captured by the number of prior alliances in common. Similarly, Okamura and Vonortas (forthcoming)

\footnotetext{
${ }^{27}$ For details on the econometric techniques usually applied in these studies see Krackhardt (1988). 
define a dummy variable called familiarity, which signals the existence or not of a previous alliance between the two. Second, they consider a variable structural embeddedness defined by the number of partners in common. Finally, they define a positional embeddedness variable, measured by the mean of centrality of the two firms. ${ }^{28}$ These three measures of embeddedness differ since their focus on the network is different, shifting from local to global. Relational embeddedness measures the relation between two firms only. Structural embeddedness considers the close neighbours of two firms and positional embeddedness considers the whole network structure since it is based on a global measure of centrality. ${ }^{29}$ Nevertheless, all these measures of embeddedness in previous partnerships, although differently conceptualised and measured, affect the probability of a new alliance.

One of the most interesting results in Gulati and Gargiulo (1999) is that the structural properties of the network itself affect the magnitude of the effects of the three kinds of embeddedness on the probability of establishing a new link. According to these authors, the emergence of a differentiated structure, with some organisations positioned at the core and others in more peripheral positions, augments the information contained in the network. Observing the differences among organisations in terms of network position provides a better understanding of their competences. The network is more informative, and the systematic uncertainty faced by organisations decreases. The results show that the emergence of a differentiated structure (e.g. core-periphery) directly affects the probability of participating in a new alliance. Moreover, the effect of positional embeddedness increases as a differentiated structure emerges.

The evolution of a partnership network towards a definite structural pattern with some central organisations, is important for the information content of the actual network. However the emergence of such a structure is not certain. For instance, in some new extremely dynamic, innovation-driven industries it can be difficult to observe this pattern. ${ }^{30}$ According to Galuti and Gargiulo, "organisations in such industries would face extremely high levels of uncertainty at the time of building cooperative partnerships because they would lack the guidance of embeddedness mechanisms” (Gulati and Gargiulo, 1999 p. 1478). The main implication of this result is that sectors matter. However, to the best of our knowledge, there are no other works that present a cross-sector analysis of how different network structures affect the informative content of a network.

When a network of collaborations is not informative, however "it is conceivable that others networks may provide alternatives to the network of prior alliances as a source of information tapped by organisations” (Gulati and Gargiulo, 1999 p.1478). In a recent paper, Cantner and Graf (2006) implicitly follow this line of research. They study the determinants of cooperative linkages among innovative

\footnotetext{
${ }^{28}$ Okamura and Vonortas (forthcoming) do the same, although they name this variable structural embeddedness.

${ }^{29}$ Gulati and Gargiulo (1999) use the Bonacich centrality index (this is based on the principal eigenvector of the adjacency matrix and, broadly speaking, the centrality of a node is proportional to the sum of centralities of the nodes it is connected to); Okamura and Vonortas (forthcoming) consider betweenness.

${ }^{30}$ Gulati and Gargiulo's analysis focuses on fairly mature and stable sectors: new materials, automotive products and industrial automation.
} 
organisations located in Jena, using patent data. ${ }^{31}$ Results show that social networks established through labour mobility matter in determining formal collaborations between organisations. Their analysis is at level of dyads, focusing on the determinants of collaborations (a common patent) between pairs of organisations. They split the period of analysis into two sub-periods, and analyse the determinants of collaboration in the second period. ${ }^{32}$ The results indicate the role played by short term interpersonal linkages in shaping networks of cooperation. ${ }^{33}$ The observation that two organisations are linked because some of their respective employees were former colleagues affects the probability that these two organisations enter into a formal collaboration. As workers or scientists move between jobs, they carry knowledge about the competencies and trustworthiness of former colleagues and employers. This result is in line with those based on case-study and survey data analysis.

In sum, the papers reviewed above show that (i) social relations affect the choice of partner in a R\&D alliance. Embeddedness in a thick web of relations is a key factor in establishing a new partnership. Also, embeddedness increases the informative capacity of the overall network. And (ii) that this depends either the presence of stable, well-structured networks of organisations or (iii) on an effectively functioning social network of scientists and engineers.

\subsection{Innovative performance}

In this section we review the main findings of empirical studies investigating the role of networks in innovation. First, the aggregate innovative performance of the overall network is considered; second, the innovative performance of single organisations and how this is affected by network features (e.g. centrality) is examined. ${ }^{34}$

\subsubsection{Innovative performance at network aggregate level}

The group of studies analysing the innovative performance of networks focuses mainly on their structural properties, and particularly whether the network structure displays small-world properties. ${ }^{35}$ The small-world type network structure is particularly important for both the generation and diffusion of knowledge (Cowan and Jonard, 2004). On the one hand, a high degree of density and redundancy of linkages within local cliques ensure the formation of a common language and communication codes among networks' participants, which enhance reciprocal trust and support the diffusion of complex and tacit knowledge, thereby increasing the rate of production of new knowledge. On the other hand, the shortcuts linking local

\footnotetext{
31 They base their analysis on patents (German patent office) applied for in the period 1995-2001 for all sectors with at least one inventor located in Jena.

32 1995-97 and 1999-2001

${ }^{33}$ Another determinant is the technological overlap between two organisations. The technological complementarity hypothesis is confirmed in their analysis.

${ }^{34}$ Two extensive reviews of empirical studies linking networks and innovation are Zirulia (2005), which focuses on formal R\&D agreements, and Powell and Grodal (2005), which reviews the role of formal and informal ties on innovation.

${ }^{35}$ As briefly explained at the end of section 3, small-world networks are characterized by tightly linked local cliques connected to each other through a few shortcuts, i.e. high degree of local clustering and short path length.
} 
cliques to different and weakly connected parts of the network ensure the rapid diffusion of new ideas throughout the network and retain some openness to new sources of knowledge, thereby mitigating the risks of lock-in that could arise in contexts of densely connected cliques.

Other authors have emphasised that small-world properties can arise because of the presence of a few very well connected actors, i.e. hubs ${ }^{36}$ (Barabasi, 2002). More specifically, the degree distribution of actors seems to follow a power-law distribution, in which a few actors have a disproportionately high number of connections, while the vast majority have only one or few connections. These hubs serve as the common connections mediating the short path lengths between other nodes and therefore play a key role in ensuring the fast and reliable diffusion of knowledge to even the most peripheral nodes in the network.

The small-world structure can also be seen as reconciling two different views at the centre of debates in sociology, and recently also in economics and business studies. The first is based on the work of Coleman (1988) and argues that being embedded in a very dense, interconnected, highly cohesive network brings benefits by enhancing trust among individuals and thus encouraging joint activities and the sharing of tacit and complex knowledge (e.g., Walker et al., 1997, Uzzi and Spiro, 2005). The second view derives from Burt's (e.g. 1992) work on structural holes. The argument here is that when the objective is to access new knowledge, being embedded in a very dense and strongly cohesive network may be harmful to individual learning processes by producing high levels of redundancy, thereby reducing the amount and quality of accessible information. According to this view, efficiency in accessing knowledge is achieved by limiting the number of redundant contacts, and by a positioning across structural holes, i.e. by linking individuals that are not otherwise connected to each other. ${ }^{37}$ Individuals positioned in structural holes are able to broker knowledge flows across unconnected groups (e.g., Gargiulo and Benassi, 2000). It has been shown empirically that both configurations positively affect innovation. Yet, when they are tested for the same kind of benefit, the effectiveness of a cliquish structure is superior, i.e. the magnitude of the benefit is higher than is the case for structural holes (Ahuja, 2000a).

Watts and Strogatz (1998) developed a formal model to show that it is possible to build networks that are both “cliquish” (consistent with Coleman's argument) and characterised by short average distances, consistent with Burt's view. Cowan and Jonard (2004) applied this framework to study the process of creation and diffusion of knowledge. A simulation model is used to assess the effectiveness of different network structures in creating and diffusing knowledge. Empirical support for this hypothesis is provided by those studies that identify the existence of small worlds in several networks where knowledge creation and diffusion are relevant, such as networks of strategic alliances (Verspagen and Duysters, 2004; Breschi and

\footnotetext{
${ }^{36}$ A hub can be defined as a node with a very large number of connections or, alternatively, as a node, which in its role of a network connector is very influential in connecting nodes that would otherwise remain unconnected.

${ }^{37}$ Burt's concept of structural holes can be seen as a generalisation of Granovetter's idea of weak ties. Indeed, the discussion on cliques, structural holes and small worlds can be related to the concept of strong and weak ties "If each person's close friends know one another, they form a closely knit clique. Individuals are then connected to other cliques through their weak rather than their strong ties. Thus, from an aerial view of social networks, if cliques are connected to one another, it is mainly by weak ties" (Granovetter, 2005, p. 34). Therefore, it is plausible to consider links inside cliques to be strong ties, and links outside cliques (bridging structural holes) to be weak ties.
} 
Cusmano, 2004; Roediger-Schluga and Barber, 2006) and networks of scientists (Goyal et al., 2006). However, the results of a test conducted at the level of regional networks in the US by Fleeming et al. (2006) for the influence of small world properties on innovative performance were ambiguous. The authors constructed networks of inventors in 337 Metropolitan Statistical Areas, assuming that two inventors were socially linked if they were listed as patent inventors. They regressed the number of patents at regional area on the structural properties of the network (average distance and average cliquishness). They found that the degree of "small-worldness" (i.e. how much the network mirrors a small world) did not significantly affect the aggregate performances of inventors (in terms of patents).

\subsubsection{The Innovative performance of network participants}

Most firms enter into technological agreements or informal knowledge networks to improve their technological capabilities and to foster their innovative performance. Several studies provide empirical evidence documenting strong positive relationships across many industries between alliance formation and some proxy for innovation (Ahuja, 2000; Powell et al. 1996 and 1999; Stuart, 1998 and 2000; Walker et al. 1997). These contributions mainly focus on high tech industries (e.g. biotech, pharmaceuticals, telecommunications), and most use patents as proxy for innovation. Relatively few studies have focused on informal networks (Schrader, 1991), and even fewer have targeted low-tech sectors (Boschma and ter Wal, 2006).

Concerning studies on formal $\mathrm{R} \& \mathrm{D}$ collaboration and innovative performance, there is a prominent line of research investigating the causal link between a firm's position in the network (e.g. firm degree centrality) and innovation. Powell at al. (1996), using a sample of 225 dedicated biotech firms for the period 1990-1994, found that degree centrality positively affects sales growth. This work assesses the effect of participating in R\&D alliances on organisational learning. Four hypotheses are tested: a) the greater the number of a firm's R\&D alliances and the greater its experience in managing them, the greater the number of its non-R\&D collaborations; b) the greater the number of a firm's $R \& D$ alliances and the greater its experience in managing them, the more the firm is centrally connected; c) the greater the firm's centrality in the network and its experience in managing $R \& D$ alliances, the more rapid will be its subsequent growth; $d$ ) the greater the firm's centrality, the greater will be its number of subsequent $R \& D$ alliances. The results support all four predictions. A similar study (Powell et al., 1999) on biotech firms for the period 1988-99 confirms that centrality is a significant determinant of innovation. The number of $R \& D$ collaborations appears as one of the key variables explaining the increase in firms' patenting activity. In addition, as in Powell et al. (1996), experience in networking has a major and positive influence on the rate of patenting, though this rate declines as experience increases. As stressed in Powell and Grodal (2005), this latter result suggests the existence of some declining returns to network connectivity, which requires further investigation. Overall these studies describe a self-reinforcing process in which collaborations attract new partners, and firms accumulate experience in managing collaborations and in this way increase their 
centrality in the innovative network, which enables them to attract new partners. The presence of a virtuous cycle which runs from R\&D alliances to innovation and growth is confirmed by Ahuja (2000b) and Stuart (2000). Stuart shows that in the semiconductor industry patenting rate, and other measures of firm performance (e.g. sales growth, revenues), are positively affected by the number of alliances. Similarly Baum et al. (2000), in a sample of 142 biotech start-ups, find a positive relationship between patenting and the number of alliances.

A key paper in this group is Ahuja's (2000a) work on the role of direct and indirect ties in firm performance. Drawing on a sample of 97 firms in the world chemical industry, the author assesses the effect of three dimensions of a firm's ego-network ${ }^{38}$ (i.e. direct ties, indirect ties and structural holes) on its innovation output. Innovation is measured by patents (period 1982-1992), and collaboration data are based on several sources (archival, databases, magazines, sectoral publications) for the period 1981-1991 (there is a one year lag between collaboration and patenting). The dataset includes 268 joint ventures and 152 joint research agreements (collaborations that do not imply the creation of a new organisation). Overall, the results suggest that both direct and indirect ties positively affect innovation, though indirect ties have a smaller impact. The findings suggest that Coleman's closure argument, i.e. higher cliquishness is desirable for innovation, prevails over Burt's structural holes argument. This may be due to the fact that direct contacts enable firms to build trust and reduce opportunisms, which facilitates the transfer of more idiosyncratic knowledge.

Among the studies on informal know-how trading and firms' innovative performance, a notable study is Schrader (1991). His empirical exercise, unlike the studies reviewed above, is not based on inferential analysis. He adopts a qualitative approach, in which a sample of managers (see Section 4.1.1 for more details) were asked to rate, on a likert scale, the economic success of their firms in comparison with the industry average. The results suggest a positive relationship between the participation of a firm's employees in informal information trading and firm performance.

Boschma and ter Wal (2006), along the lines suggested by studies on organisational learning (Powell et. al. 1996), investigated the link between a firm's centrality in the knowledge network to innovation performance. The study focuses on a sample of firms in the footwear cluster of Barletta (Italy) and is based on survey data (for more details see Section 4.1.1). The methodology comprised testing the correlation between the firm's network position (i.e. degree and betweenness centrality) and innovative performance (product and process innovation, share of innovative sales over sales in the previous year). The authors were interested in testing the importance of local compared to non-local ties, so indexes for the network positions of firms we reconstructed to account for geographic distance. This allows them to measure the impact of local versus non-local networks on innovation. The findings show the existence of a positive relationship and

\footnotetext{
${ }^{38}$ Ego-network (ego-centred network) "consists of a focal actor, termed ego, as a set of alters who have ties to ego, and measurements on the ties among these others” Wasserman and Faust, 1994, p.42.
} 
that connections with non-local partners are important for innovation in bringing new knowledge into the firm.

\section{THE BOUNDARIES OF SOCIAL RELATIONS: DEFINITION AND MEASUREMENT ISSUES}

In this section we look more closely at how the empirical literature deals with interpersonal relations. Some scholars have underlined that any formal tie lies within a sea of informal social relations (Powell et al. 1996). However, few studies have investigated the extent to which inter-organisational networks depend on social ties. We focus on the studies discussed in the previous sections in order to show the extent to which they incorporate, either implicitly or explicitly, the conceptual framework depicted in Figure 1.

We look at how social relations have been defined and measured. Some studies use proxies to account for them (e.g. co-invention). However, proxies have their methodological and conceptual drawbacks. Problems can arise based on the fact that they only partially reproduce the phenomena they are built for. At the same time there are studies that implicitly assume the pre-existence of a social glue (e.g. clusters studies), while focusing on the measurement of formal inter-firm knowledge linkages, which may lead to misleading interpretations of the role and stability of formal agreements. Overall, conceptual and measurement ambiguity are the norm in many of these studies, which does not help in the understanding and assessment of the role of social relations in knowledge exchange and related activities (e.g. appropriability, transferability, policy measures for technology transfer).

\subsection{Social relations in analysis dealing with case studies, survey and questionnaire data}

The definition of social ties is a critical issue in the social network literature (Marsden, 1990) and particularly in studies of informal networks and knowledge transfers, because "the most valuable information is communicated by informal channels” (Rogers, 1982). Thus, it is a serious concern for firms to understand whether their employees' informal contacts lead to knowledge leakages and, if so, to learn how to manage and ultimately limit them, in order to prevent harmful effects. Conversely, if informal contacts entail information trading, firms will evaluate their potential benefits, and will probably be keen to encourage external interactions (Schrader, 1991).

Some studies dealing with informal networks and knowledge flows explicitly define social ties. In his study on mini-mills companies, Schrader builds a summary variable (using factor analysis of data) to proxy social ties. This variable, labelled 'strength of relations/friendships', includes questionnaire variables describing the types of relations that exist between the senders and receivers of information, which include the existence of a friendship between the senders and the seekers of information; the duration of the friendship; the degree of cooperativeness of the seeker. The variables so defined account for several dimensions of a social relation; in particular they qualify it and enable information related to the relevance, nature and content of the messages transferred through it to be gathered. The variable friendship indicates 
that the relation between the sender and the seeker predated the exchange, and more importantly is independent of it. This is key information as it provides the information that those involved in the exchange would take with them their network of contacts were they to change jobs. This of course could damage the firm's business relationships, depending on the importance of the network of relations developed by the employee. It then becomes important to know more about the position in the network of each employee engaged in knowledge transfers, e.g. whether she acts as bridge for the firm (i.e. she connects two otherwise unconnected group of actors either inside or outside the firm boundaries) or whether or not she is a central actor in the network. This type of analysis, which requires the collection of detailed relational and attributional data, has been developed in the literature on network data (i.e. co-inventors; survey data), which we examine later in this section.

Important information can be derived from attributional data, such as duration of friendship and degree of cooperativeness. They allow the nature of a relation to be distinguished by providing evidence on its stability, and enable inferences about the potential degree of reciprocity related to the exchange. Long lasting and cooperative relations are generally built on trust, and trustworthiness and reciprocation are the basic ingredients of knowledge transfers.

Some studies define social ties in terms of friendship or kinship, such as Lissoni’s (2001) work on the Brescia mechanical cluster. In his analysis, rather than implicitly assuming that formal collaborations rely on personal interactions, the author defines the relevant social community. As in the literature on information trading (Carter, 1989; von Hippel, 1987; Schrader, 1991), this is formed by "small working groups that work on a mutually recognised subset of knowledge issues, and who at the very least accept some commonly understood procedural authority as essential to the success of their collective knowledge building activities” (Cowan et al. 2000: quoted in Lissoni, 2001: 1482). These interpersonal contacts give rise to inter-firm knowledge exchanges. Lissoni's paper also provides convincing evidence that interactions are not established by individual technicians, but rather arise out of successful commercial partnerships, and respect firms' appropriation strategies. This confirms that firms are aware of the risks of leakages and that, as shown by other studies (Dahl and Pedersen, 2004; von Hippel, 1987; Schrader, 1991), they discourage or forbid interactions with employees from other firms through the inclusion in contracts of competition clauses. Dahl and Pedersen's (2004) work on the NorCom telecommunication cluster, for example, found that $16.2 \%$ of engineers had signed some type of non-disclosure agreements.

Dahl and Pedersen also explored the genesis of engineers' relationships. The survey on which this study was based asks for information about how relations were established; it distinguishes between former colleagues, classmates and private friends. It is interesting that most contacts are established with former colleagues. This strengthens the argument that mobility is important in extending networks of informal contacts, and shows that as engineers move from one firm to another, they continue to collaborate and interact with former colleagues. However, it cannot be assumed that if social relations continue after a 
technician moves jobs this will be an effective channel for the accessing and sharing of knowledge. We discuss this issue in more detail for the case of inventors (see section 5.2).

The studies on informal knowledge flows that use socio-metric techniques and graph theory (we refer to the studies reviewed in section 4.1.1) do not explicitly investigate the genesis of relationships (Boschma and ter Wal, 2006; Giuliani and Bell, 2005; Giuliani, 2007; Morrison and Rabellotti, 2005). They focus on the cognitive dimension of the relationship, that is whether the participants (e.g. engineers) share a given piece of information in an advice network. If the information requested is provided, the sender and seeker are linked by a tie. This connection is a measure of a knowledge flow between two individuals and can be interpreted as an inter-firm knowledge flow between their employing firms. However, this analysis says little about the social content of the underlying relationship. This is not to say that an advice network cannot be seen as a social relation in its own right (Cross at al. 2001). Rather, what is important here is that we cannot infer much about the extent to which individual action, for example a technician's decision to activate or use a given contact, is affected by the constraints imposed by the social structure or, conversely, if her actions are delimited by firms' strategies. In these studies, we do not know whether it is the firms that set the boundaries of an individuals' social relations, which in turn may determine the extension of the advice network itself.

\subsection{Social relations in analysis dealing with dataset}

Methodological concerns arise from an examination of studies based on co-inventor data (see the final paragraphs of Section 4.1.1), which are by far the most diffused data for the analysis of informal knowledge flows. Two issues require particular attention. First, there is a problem of validity (i.e. "the extent to which a measure actually measures what it is intend to measure” Wasserman and Faust, 1994:57), or the need to understand better what kind of relations are implied by co-participation in patenting activity. Second, it is necessary to define the boundaries of the population, that is, whether the inventors' network is a real representation of the relevant community of experts. The studies reviewed in previous sections based on patents only partially deal with these issues, leaving many questions open.

The first issue is debated less in the literature. The assumption is that if a group of individuals participates in a research activity that results in a patent application, these individuals will develop a social and cognitive relationship which keep them linked. A team of researchers involved in a research activity is comprised of individuals necessarily sharing a common language or code (Cowan et al., 2000), each endowed with personal knowledge (Polanyi, 1962). They commit to a collective process, which in the case of patenting produces some 'novel' results. ${ }^{39}$ In this process, these researchers develop a common understanding, i.e. know-how (which will differ according to the skills, knowledge and positions of these individuals in the team), and also knowledge of the competences and skills of the other members of the team

\footnotetext{
${ }^{39}$ A patent must satisfy some criteria of novelty in order to be approved. 
(i.e. know-who). Scholars often assume that the former implies a cognitive relation (e.g. common understanding) and the latter enables the establishment of a social relation (e.g. a channel of collaboration), which could play a key role in building a network of inventors. This is plausible in general terms, although in terms of its dynamics perhaps less so. The studies previously reviewed (e.g. Breschi and Lissoni, 2004; and Singh, 2005) mostly analyse patenting activity over a long time period (e.g. more then 15 years) and assume that cognitive and social relations persist over the entire period. ${ }^{40}$ This assumption is even more significant if the role of cross-firm inventors (i.e. mobile inventors) is considered. Cross-firm inventors are responsible for the connectivity of networks and are seen as the main determinants of knowledge flows. It is reasonable to assume that cognitive relations will survive mobility, but how many social relations survive a change of employer is less straightforward. Social relations are established in specific organisational contexts and presumably operate according to well defined sets of rules and arrangements about disclosure and communication. When the organisational context and the set of rules change, as in the case of cross-firm inventors, it cannot be assumed that: (i) social relations will survive; or (ii) that social relations can be used for effective informal transfer of know-how. There are relatively few studies (Lissoni 2001; Dahl and Pedersen 2004), based on anecdotal evidence and case-studies, that provide contrasting evidence on this issue. Therefore, whether a network of inventors can be considered a social network or merely a map of cognitive relations among individuals and organisations has still to be understood.

Breschi and Lissoni (2004) explicitly address the issue of whether inventors are the relevant community of experts. Their objective is to understand whether "the interpersonal exchanges between inventors are no more than a tiny subset of all the exchanges enabling inventors to achieve their results” (p.631). Their work sheds some light on the issue, though they are unable to provide the reader with a firm conclusion.

Their analysis begins with a careful examination of the 'disclosure rules' that patent applicants must satisfy (see Breschi and Lissoni 2004, in particular section 3.2). These rules relate to the part of an invention that has to be described in the patent document (and thus disclosed to others) before the patent is granted assigning the patent applicant temporary monopoly power over her invention. However, as the authors argue, none of these rules, however defined, are strong enough to make all the information immediately accessible.

How much information has to be disclosed is defined by the patent system, which requires that patent documents must be accessible to someone with an "average experts' understanding”. This means, according to Breschi and Lissoni (2004: 631), that:

inventors (and their legal aids) bear in mind a well-defined reader's profile when drafting a patent document. In turn, such profile reminds of a community of experts, whose core the inventors themselves, their colleagues (within and outside the organisations they work for), and the patent examiners; anybody whose competencies are not up to the profile are excluded.

\footnotetext{
${ }^{40}$ Fleeming and Frenken (2006) in their analysis of regional networks of inventors assume that co-invention links persist for no more than 5 years.
} 
Thus, the authors presume that information left out of the invention description would be easily accessible only to the community of experts with whom the reader's profile corresponds. Moreover, given the narrow definition of patent fields, and the high degree of specialisation of inventors, they conclude that the network of inventors "may possible represent the most immediate and influential social environment from which inventors draws ideas and information, at least for the technical contents of their patents” (p. 632).

Similarly, studies of formal networks (e.g. networks based on R\&D alliances) raise similar methodological issues, mainly the cognitive and social aspects of the formal agreements signed by two or more organisations. An R\&D alliance was defined by Zirulia (2005: 3), "as common interests between independent industrial partners, which are not connected through majority ownership, and in which R\&D is at least part of collaborative effort, through some arrangements for transferring technology or joint research.”(p. 3), which suggests that the parties in such agreements are involved in knowledge exchange in the form of shared resources. However, the literature usually assumes that "beneath the formalities of contractual agreements, multiple informal interpersonal relationships emerge across organisational boundaries, which facilitates the active exchange of information and the production of trust that foster interorganisational cooperation” (Gulati and Gargiulo, 1999, p. 1445).

Therefore, R\&D alliances imply two types of knowledge exchange: (i) formal agreements; and (ii) knowledge spillovers. The existence and effectiveness of the latter channel of knowledge transmission assumes that better innovative performance is achieved by those organisations with greater social resources (however measured). All the explanations proposed by the studies reviewed in previous sections (see in particular section 4.3.1.) are based on this assumption. However, to the best of our knowledge, little systematic research has been conducted to assess the empirical validity of this key assumption.

Owen-Smith and Powell's (2004) paper is an exception here. Owen-Smith and Powell show that under certain conditions data on formal collaborations ${ }^{41}$ can effectively capture (and measure) informal knowledge exchanges. The study analyses innovative performance (measured by numbers of patents) of diagnostic biotechnology firms (DBF) located in the Boston area. The authors construct two networks: the first includes only organisations located in the region and the ties among them, the second covers all DBFs, wherever they are located, that have a connection to a Boston based organisation. ${ }^{42}$ The results show the different ways in which the two networks affect the innovative performance of DBFs. The findings suggest that in networks embedded in regional clusters, as in the case of the first network, membership (of the network) is enough to improve innovative performance; in other words the actors' position in the network (i.e. centrality) is not significant. The reason for this is that being connected to the local giant component signals that firms are members of the underlying local technological community and that they are able "to capture geographically bounded information spillovers by providing an entry ticket to rich informal networks

\footnotetext{
${ }^{41}$ They formal inter-organisational arrangements signed in the period 1988-99 by biotech firms located in the Boston area worldwide.

${ }^{42}$ The organisations in the first network are included, but the ties that make up the first network are excluded.
} 
of academic and industrial scientist, while also rising visibility in the local labor market” (Owen-Smith and Powell, 2004: 15). As far as the worldwide network (i.e. the second one) is concerned, the effect of being part of the network dramatically changes: membership is not enough to achieve better innovative performance and centrality (measured by betweenness) becomes a key explanatory variable. The reason for this is that "physical distance and the dominance of organizations committed to proprietary uses of knowledge render formal ties more closed, limiting the viability of informal network and labor market mobility as mechanisms for information transfer” (Owen-Smith and Powell, 2004, p.16; emphasis added).

The results are similar if regional embeddedness is substituted for a node's institutional features. For example, if a network is characterised by heavy participation of organisations pursuing public goals (e.g. universities), then being part of this network is enough to gain in terms of patents achieved, while centrality it is not significant.

The methodological implications are twofold. First, the effect of formal ties (and a formal network) depends on the non relational features (e.g. physical location and institutional anchors) of the organisations participating in. Second, the interpretation of formal collaboration as a proxy for formal and informal knowledge exchange requires more research.

\section{CONCLUSIONS}

An increasing number of empirical and theoretical contributions is adopting a social network perspective to analyse the innovative activity and performance of economic actors. The view that "[d]espite ... organisational arrangements, the physical interaction takes place between people” (Cantner and Graf, 2006, p. 464) has generated much empirical research showing that interpersonal networks are important 
channels for the diffusion of information and knowledge. The object of analysis has become, at least implicitly, a system of two interacting networks, an inter-organisational network and an interpersonal network, and "[t]he extent to which inter-organisational ties are contingent upon relations among individuals is a key question for scholarly research” [Powell and Grodal, 2005, p. 61]

The empirical literature along these lines is highly heterogeneous in many respects, in particular in terms of its aims (e.g. new relation vs. innovative performance), application context (e.g. sectors vs. regions), methodology and data used (e.g. case studies vs. econometrics), literature background (e.g. strategic vs. geographic studies). Yet, it displays some commonalities in terms of raising very similar questions related to methodological issues or research priorities. In what follows, we briefly summarise the most important issues highlighted in the literature and some critical points that emerged from the reviewing process.

Most attention has been paid to informal trading in know-how which has been defined in terms of the technical knowledge that engineers and other technically oriented personnel exchange with peers in other firms without any formal collaboration arrangements between the firms in which they are employed (Carter, 1989). Some studies (e.g. Schrader 1991) conclude that individuals usually enlist help from people they know personally (i.e. that they are socially connected to), while others (e.g. Lissoni, 2001) point out that the content of what is traded is greatly influenced by the firm's strategy. This complex mix of social relations and strategic behaviour (Roger, 1982) is difficult to analyse and the origin of a link or whether the persistence of a relation depends exclusively on the individual's or the firm's actions is not straightforward. There is also no agreement in the empirical literature, e.g. Lissoni (2001) vs. Dahl and Pedersen (2004). This ambiguity has important consequences for the already complex problem of measuring the relations that link individuals and organisations, as discussed in section 5. Definition of the relevant social community for knowledge transfers and the way researchers measure it are key methodological issues, which call for further investigation. Several examples discussed in the review indicate severe problems related to the validity and accuracy of indicators. For instance, in networks built using questionnaire data, it is not entirely clear whether the relations observed were established by technicians or firms, e.g. Giuliani and Bell 2005. Similarly, in networks based on patent data, it is not clear whether co-patenting is a good indicator of stable social relations, especially if these relations are studied over long time periods.

The role of the overall structure of networks is an under analysed issue. One of the most interesting results in Gulati and Gargiulo (1999) is that the informative content of networks depends on the overall structure of the network. From an analytical point of view, this means that the explanatory power of different measures of centrality (e.g. local vs. global measures) may depend on the actual structure of the network. However, the different effects on networks as their structural properties evolve, are rarely studied. In more general terms, the literature seems to lack dynamic analysis of the evolution of interpersonal and interorganisational networks.

Indeed, the existing empirical analyses adopt a predominantly static approach, focusing on network structures measured at a given point in time (or across a given time span). Most network analyses based on 
survey data are essentially static. If the time dimension is considered, ${ }^{43}$ this provides information only about the time that the relationship began and it is still difficult to trace its evolution over time. Thus, the main limitation in these studies is lack of longitudinal data. The surveys cover only few years and are generally limited to specific areas. Extensive innovation surveys including relational data would be extremely costly, and thus it is unlikely that they would be designed and administered to firms. Some longitudinal panel datasets do exist based on data on R\&D alliances and patents. However, empirical studies using these datasets have rarely focused on the dynamic properties of networks, and are mainly involved in examining the impact of the actors' positions at given points in time on firm performance in subsequent periods (e.g. Stuart 2000). A notable exception, as discussed in our survey, is Fleeming and Frenken (2006) which looks specifically at the way networks emerge and evolve over time. In doing so, the key factors underpinning the formation of a network of inventors at regional level are identified. Further research along these lines could make a valuable contribution to the literature on the determinants of formal and informal networks.

Another aspect that has received little attention is the sectoral perspective. Several studies deal with high-tech sectors, very few with low-tech and non manufacturing sectors (notable exceptions are studies on informal knowledge networks, Section 4.1.1), and there are no published studies that compare different sectors in order to understand specificities and commonalities. Comparative approaches more generally have rarely been adopted. Comparisons of sectors, case-studies, regional areas, organisations might help to identify idiosyncratic and contextual specificities (e.g. sectors, institutions, etc.). Moreover, more comparative studies are need to augment the literature in this field and the robustness of results in order to extend their generalisability.

From a methodological perspective, the review shows that social network analysis is a versatile and powerful analytical tool for studying knowledge transfers. Indeed, social network analysis can be easily combined and integrated with other empirical instruments, either with qualitative methods (see Fleeming and Frenken, 2006) or econometric models (several studies). In addition, it enables clear identification and qualification of the actors (i.e. nodes) and relations (i.e. edges) involved in knowledge exchanges, and provides a visual representation of knowledge flows. The literature includes studies on the role of gatekeepers of knowledge, i.e. individuals/organisations that bring new knowledge into their research/industry teams, and to brokers, i.e. individuals/organisations that connect actors that would otherwise be disconnected. This analysis helps to unravel the complexity of the knowledge diffusion processes, and the key mechanisms and players.

Future research could explore the interplay of different social communities, for example, of networks of inventors and networks of scientists. By combining patents (which measure the former) and bibliometric data (which measure the latter), it could focus on the structural properties of these networks and demonstrate how and whether they affect one another. Similarly, research could focus on the interplay of networks of

\footnotetext{
${ }^{43}$ In questionnaires respondents are often asked to report about the starting date of a relationship, or to provide information about the relationships developed in a given time period.
} 
R\&D projects and networks of diffusion based on partnership projects (FPs and regional programmes). Overall, empirical approaches combining different methodologies (e.g. network analysis, qualitative methods, econometrics) and different types of data (e.g. bibliometric, survey, patent) would help to provide a better understanding of the role of social networks in shaping economic actions. 


\section{REFERENCES}

AHUJA, G. (2000a), “Collaboration networks, structural holes, and innovation: a longitudinal study”, Administrative Science Quarterly, 45, 425-55.

AHUJA, G. (2000b), "The duality of collaboration: inducements and opportunities in the formation of Interfirm Linkages”, Strategic Management Journal, 21, 317-343.

ALMEIDA, P., KOGUT, B. (1999), "Localisation of knowledge and the mobility of engineers in regional networks”, Management Science, 45(7), 905-917.

ARROW, K., 1987. "Reflection on the essays”, in G. FEIWEL (ed.) Arrow and the Ascent of Modern Economic Theory, NY University Press, pp.685-689.

AUDRETSCH, D.B., FELDMAN, M.P. (1996), "R\&D spillovers and the geography of innovation and production”, American Economic Review 86(3), 630-640.

BALCONI, M., BRESCHI, S., LISSONI, F. (2004) "Networks of inventors and the location of academic research: An exploration of Italian data”, Research Policy 33(1), 127-45.

BARABÁSI, A.-L. (2002). Linked: The New Science of Networks, Perseus, Cambridge, MA.

BAUM, J. A., CALABRESE, T., SILVERMAN, B. S. (2000), “Don’t go it alone: Alliance network composition and startups' performance in Canadian biotechnology”, Strategic Management Journal 21, 267-294.

BECATTINI, G. (1990), 'The marshallian industrial district as a socio-economic notion' in PYKE F., BECATTINI G., SENGENBERGER W. (eds.), Industrial Districts and Inter-Firm Cooperation in Italy, ILO, Geneva, 37-51.

BORGATTI, S.P., EVERETT, M.G., (1999), ”Models of core/periphery structures”, Social Networks, 21, 375-395. 
BOSCHMA, R.A., TER WAL, A.L.W. (2006). "Knowledge networks and innovative performance in an industrial district. The case of a footwear district in the South of Italy," Papers in Evolutionary Economic Geography (PEEG) 0601, Utrecht University, Section of Economic Geography.

BRESCHI, S., CUSMANO, L. (2004) "Unveiling the Texture of a European Research Area: emergence of oligarchic networks under EU Framework Programmes” in International Journal of Technology Management 27: 747-772.

BRESCHI, S., CASSI, L., MALERBA, F., VONORTAS, N. (2007), Networked Research: European Policy Intervention for Information \& Communication Technologies. Mimeo, Bocconi University.

BRESCHI, S., LISSONI F. (2001a), "Knowledge Spillovers and Local Innovation Systems: A Critical Survey”, Industrial and Corporate Change, vol. 10 n. 4, 975-1005.

BRESCHI S., LISSONI, F., (2001b), “Localised Knowledge Spillovers vs. Innovative Milieux: Knowledge ‘Taciteness’ Reconsidered”, Papers in Regional Science, 90, 255-273.

BRESCHI, S., LISSONI, F. (2004) "Knowledge network from patent data: methodological issues and research targets” in Schmoch U, Moed H., and Glanzel W. (Eds) Handbook of quantitative science and technology research, Kluwer; p. 613-643.

BRESCHI, S., LISSONI, F. (2006) “Cross-firm inventors and social networks: localised knowledge spillovers revisited”, Annales d'Economie et de Statistique.

BRUSCO, S. (1982) “The Emilian model: productive decentralisation and social integration” Cambridge Journal of Economics, 6, pp. 167-184.

BRUSCO, S. (1996) “Global systems and local systems”, in Cossentino F., Pyke F., Sengenberger W. (eds.), Local and regional response to global pressure: the case of Italy and its industrial districts, ILO, Geneva, 147-158.

BURT, R. S. (1992), Structural Holes: The Social Structure of Competition, Harvard University Press. 
CAMAGNI, R., (1991), "Local milieu, uncertainty and innovation networks: towards a new dynamic theory of economic space”, in CAMAGNI R., (ed.), Innovation networks: Spatial Perspectives, London: Belhaven-Pinter, 121-144.

CANTNER, U., GRAF, H. (2006) "The network of innovators in Jena: An application of social network analysis”, Research Policy, 35, 463-480.

CAPELLO, R., FAGGIAN, A., (2005), "Collective Learning and Relational Capital in Local Innovation Processes”, Regional Studies, 39(1), 75-87.

CAPELLO, R. (1999), "Spatial Transfer of Knowledge in High Technology Milieux: Learning Versus Collective Learning Processes”, Regional Studies, 33, 353-65.

CARRINGTON, P.J., SCOTT, J. WASSERMAN, S. (2005) Models and methods in social network analysis, Cambridge University Press, Cambridge.

CARTER, A. P. (1989) “Know-how trading as economic exchange” in Research Policy 18: 155-163.

CASSI, L., CORROCHER, N., MALERBA, F., VONORTAS, N. (2007), Research Networks as Infrastructure for Knowledge Diffusion in European Regions. Mimeo, Bocconi University.

COHEN, S., FIELDS, G. (1999) “Social capital and capital gains in Silicon Valley”, California Management Review 41(2), pp.108-130.

COLEMAN, J.C. (1988) “Social capital in the creation of human capital” in American Journal of Sociology 94: 95-120.

COWAN, R., JONARD, N. (2004) "Network structure and the diffusion of knowledge" in Journal of Economic Dynamics and Control 28 (8): 1557-75.

COWAN, R., DAVID, P., FORAY, D. (2000), “The explicit economics if knowledge codification and tacitness”, Industrial and Corporate Change, 9(2), 211-253. 
CROSS, R., BORGATTI, S.P., PARKER, A. (2001), "Beyond answers: dimensions of the advice network”, Social Networks 23, pp. 215-235.

DAHL, M., PEDERSEN, C. (2004) “Knowledge flows through informal contacts in industrial clusters: myth or reality?” Research Policy 33:1673-1686.

DAVID, P.A., FORAY D., STEINMUELLER, W.E. (1999) "The research network and the new economics of science: from metaphors to organisational behaviours" in A. GAMBARDELLA and F. MALERBA (eds.) The organisation of economic innovation in Europe, Cambridge University Press, pp.303-342.

DE NOOY, W., MRVAR, A., BATAGELJ, V. (2005). Exploratory Social Network Analysis Using Pajek. Cambridge: Cambridge University Press.

DEGENNE, A., FORSÈ, M. (1999). Introducing Social Networks. Thousand Oaks, CA: Sage Publications.

FELDMAN, M.P. (1999) “The new economics of innovation, spillovers and agglomeration: a review of empirical studies”, Economics of Innovation and New Technology 8, 5-25.

FLEEMING, L., FRENKEN, K. (2006) The evolution of inventor networks in Silicon Valley and Boston region, Utrecht Working Paper.

FLEEMING, L., KING, C., JUDA, A. (2006) Small worlds and regional innovation, Harvard Business School, mimeo.

GARGIULO, M., BENASSI, M. (2000) “Trapped in your own net: Network cohesion, structural holes, and the adaptation of social capital” in Organization Science 11:183-196.

GIULIANI, E. (2007) “The selective nature of knowledge networks in clusters: evidence from the wine industry” Journal of Economic Geography, 7: 139-168.

GIULIANI, E., BELL, M. (2005), “The micro-determinants of meso-level learning and innovation: evidence from a Chilean wine cluster”, Research Policy, 34, 47-68. 
GOYAL, S., MORAGA, J.L., VAN DER LEIJ, M. (2006) “Economics: an emerging small world?” in Journal of Political Economy, 114: 403-412.

GRANOVETTER, M. (1973) “The strength of weak ties” in American Journal of Sociology, 78, 6, pp.13601380.

GRANOVETTER, M. (1974) Getting a Job. A study of contacts and careers. The university of Chicago Press. 1995 Second Edition.

GRANOVETTER, M. (1985) “Economic Action and social structure: the problem of embeddedness” in American Journal of Sociology, 91, 3, pp.481-510.

GRANOVETTER, M. (2005) “The impact of social structure on economic outcomes" in Journal of Economic Perspectives 19 (1): 33-50.

GRILICHES, Z. (1990). "Patent statistic as economic indicators: a survey” in Journal of Economic Literature, XXVIII, pp.1661-1707.

GULATI, R., GARGIULO, M. (2004) “Where Do Inter-organisational Networks Come From?” in American Journal of Sociology.

GULATI, R. (1995a), "Social Structure and Alliance Formation Patterns: A Longitudinal Analysis", Administrative Science Quarterly, 40, 619-652.

GULATI, R. (1995b), “Does Familiarity Breed Trust? The Implications of Repeated Ties for Contracual Choice in Alliances”, Academy of Management Journal, 38, 85-112.

GULATI, R. (1998), “Alliances and Networks”, Strategic Management Journal, 19, 293-317.

GULATI, R. (1999), “Network Location and Learning: The Influence of Network Resources and Firm Capabilities on Alliance Formation”, Strategic Management Journal, 20, 397-420. 
GULATI, R., GARGIULO, M. (1999), “Where Do Interorganizational Networks Come From?”, American Journal of Sociology, 104(5), 1439-1493.

HAGEDOORN, J. (1993), "Understanding the rationale of strategic technology partnering: interorganizational modes of cooperation and sectoral differences”, Strategic management Journal, 14, 371-385.

HANSEN, M. (1999), “The Search-Transfer Problem: The role of Weak Ties in Sharing Knowledge Across Organization Subunits”, Administrative Science Quarterly, vol. 44, pp. 82-111.

JAFFE, A.B., FOGARTY, M., TRAJTENBERG, M. R. (2000) "Knowledg spillover and patent citations: evidence from a survey of inventors" in American Economic Review.

JAFFE, A.B., TRAJTENBERG, M., (2002) Patents, citations and innovation, The MIT Press.

JAFFE, A.B., TRAJTENBERG, M., HENDERSON, R. (1993) "Geographic Localisation of Knowlwedge Spillover as Evidenced by Patent Citations” in The Quarterly Journal of Economics, 108, 3, pp.577598.

KEEBLE D., WILKINSON F., (1999), "Collective Learning and Knowledge Development in the Evolution of Regional Clusters of High-Technology Smes in Europe”, Regional Studies, 33, 295-304.

KOGUT, B. (1988), “Joint ventures: theoretical and empirical perspectives”, Strategic Management Journal, 9, 319-332.

KRACKHARDT, D. (1988), "Predicting with Networks: A Multiple Regression Approach to Analyzing Dyadic Data." Social Networks, 10 (December): 359-381.

KREINER, R., SCHULTZ, M. (1993) "Informal Collaboration in R\&D. The Formation of networks across organizations”, Organization Studies, 14, pp.189-209.

LAZERSON, M.H. 1988. “Organizational growth of small firms: An outcome of markets or hierarchies?” American Sociological Review, 53: 330-342. 
LISSONI, F. (2001) "Knowledge codification and the geography of innovation: the case of Brescia mechanical cluster," Research Policy, vol. 30(9), 1479-1500.

LISSONI, F., PAGANI, M. (2003), 'How many Networks in a Local Cluster? Textile Machine Production and Innovation in Brescia', in Fornahl, D. and T. Brenner (eds.), Cooperation, Networks and Institutions in Regional Innovation Systems, Cheltenham: Edward Elgar.

MARSDEN, P.V. (1990) “Network Data and Measurement” , Annual Review of Sociology 16,pp.435-463.

MILGRAM, S. (1967) “The small world problem” in Psychology Today 2: 60-67.

MORRISON, A., RABELLOTTI, R. (2005). “Knowledge and Information Networks: Evidence from an Italian Wine Local System”, WP.174/2005, CESPRI - Università Bocconi.

MOWERY. D. C., OXLEY J. E., SILVERMAN B.S. (1998), “Technological Overlap and Interfirm Cooperation: Implications for the Resource-Based View of the Firm”, Research Policy, 27, 507-523.

NEWMAN, M.E.J. (2001), “The structure of scientific collaboration networks”, Proceedings of the National Academy of Science USA 98, 404-409.

OKAMURA, K., VONORTAS, N. (forthcoming) “Choosing a Partner”, Technology Analysis and Strategic Management.

OWEN-SMITH J. and POWELL (2004) "Knowledge Networks as Channels and Conduits: The effect of spillovers in Boston Biotechnology Community” in Organisation Science.

OZMAN, M. (2006). "Networks and Innovation : A Survey of Empirical Literature," Working Papers of BETA, ULP, Strasbourg.

POLANYI, M., (1962) Personal Knowledge: Towards a Post-Critical Philosophy, NY Harper Torchbooks. 
POLANYI, M., (1967) The Tacit Dimension, NY Doubleday Anchor.

POWELL, W., GRODAL, S. (2005) "Networks of Innovators”, in FAGERBERG, J., MOWERY, D. and NELSON, R. (Eds.), The Oxford Handbook of Innovation, Oxford University Press, Oxford, pp. 56-85.

POWELL, W. W. (1990) "Neither Markey nor Hierarchies: network form of organisations" in Research in Organisational Behaviour, pp.295-336.

POWELL, W.W., KOPUT, K.W., SMITH-DOERR L. (1996), "Interorganizational Collaboration and the Locus of Innovation: Networks of Learning in Biotechnology”, Administrative Science Quarterly, 41, 116-145.

POWELL, W.W., KOPUT, K.W., SMITH-DOERR L. and OWEN-SMITH J.(1999), “Network position and firm performance: organizational returns to collaboration in the Biotechnology Industry”, Research in the sociology of organizations.

RALLET A., TORRE A., (2005), “ Proximity and Localization”, Regional Studies, pp.47-59.

REES, A., 1966. "Information networks in labor markets" in American Economic Review. Paper and proceedings, 61, 2, pp.559-566.

ROBERT, H., RIDDLE, M. (2005) Introduction to social network methods. University of California Riverside (available online from http://faculty.ucr.edu/ hanneman/nettext/).

ROEDIGER-SCHLUGA, T., BARBER, M. J. (2006) The structure of R\&D collaboration networks in the European Framework Programmes, UNU-MERIT Working Papers, 36.

ROGERS, E. (1982) “Information exchange and technological innovation”. In Sahal D (ed) The transfer and utilization of technical knowledge. Lexington, Mass, 105-123.

SABEL, C., HERRIGEL, G., KAZIS, R., DEEG, R. (1987), "How to keep mature industries innovative” in Technology Review 90 (3), 26-35. 
SAXENIAN, A.L. (1994), Regional Advantage: Culture and Competition in Silicon Valley and Route 128, Cambridge, MA: Harvard University Press.

SCHRADER, S. (1991), "Informal technological transfer between firms: cooperation through information trading.”, Research Policy, 20, 153-170.

SCOTT, J. (2000) Social Network Analysis: A Handbook. London: Sage Publications.

SINGH, J. (2005). “Collaborative networks as determinants of knowledge diffusion patterns”, Management Science, 51, pp-756-770.

SORENSON, O., RIVKIN, J. W., FLEEMING, L. (2006). "Complexity, networks and knowledge flow.” Research Policy, 35.

STOLPE, M. (2002), "Determinants of knowledge diffusion as evidenced in patent debates: the case of Liquid Crystal Display technology”, Research Policy 31, pp. 1181-1198.

STUART, T. E. (1998) "Network Positions and Propensities to Collaborate: An Investigation of Strategic Alliance Formation in a High-technology Industry”, Administrative Science Quarterly 43, 668-698.

STUART, T. E. (2000), "Interorganizational Alliances and the Performance of Firms: A Study of Growth and Innovative Rates in a High-Technology Industry”, Strategic Management Journal 21, 791-811.

STUART, T.E., SORENSON, O. (2003), “The geography of opportunity: spatial heterogeneity in founding rates and the performance of biotechnology firms”, Research Policy, 32, 229-253.

THOMPSON, P., FOX-KEAN, M. (2005), "Patent Citations and the Geography of Knowledge Spillovers: A Reassessment”, American Economic Review, 95(1): 450-460.

TSAI, W. (2001). "Knowledge transfer in intra-organizational networks: Effects of network position and absorptive capacity on business unit innovation and performance”. Academy of Management Journal, 44: 996-1004. 
TSAI, W., GHOSAL, S. 1998, "Social Capital and Value Creation: the Role of Inter-firm Networks", Academy of Management Journal, 41 (4): 464-476.

UZZI, B. (1997) "Social structure and competition in inter-firm networks: the paradox of embeddedness." Administrative Science Quarterly, 42: 35-67.

UZZI, B., SPIRO, J. (2005) “Collaboration and creativity: the small world problem” in American Journal of Sociology 111: 447-504.

VERSPAGEN, B., DUYSTERS, G. (2004), “The small worlds of strategic technology alliances”, Technovation, 24(7), 563-571.

VON HIPPEL, E. (1987) “Cooperation between rivals: informal know-how trading.” Research Policy 16: 291-302.

WALKER, G., KOGUT, B., SHAN W. (1997), "Social Capital, Structural Holes and the Formation of an Industry Network”, Organization Science 8(2), 109-125.

WASSERMAN, S., FAUST, K. (1994), Social network analysis, New York: Cambridge University Press.

WATTS, D., STROGATZ, S.H. (1998) "Collective dynamics of "small world" networks". Nature 393: 440442.

ZIRULIA, L. (2005) Interfirm technological alliances and the evolution of industries: a survey of the empirical literature, Mimeo, Bocconi University. 